\title{
Single-cell Sequencing of Thiomargarita Reveals Genomic Flexibility for Adaptation to Dynamic Redox Conditions
}

\section{OPEN ACCESS}

Edited by:

Andreas Teske,

University of North Carolina at Chapel Hill, USA

Reviewed by:

Trinity L. Hamilton,

University of Cincinnati, USA Maria Pachiadaki,

Bigelow Laboratory for Ocean Sciences, USA

*Correspondence: Matthias Winkel mwinkel@gfz-potsdam.de Marc Mußmann mussmann@microbial-ecology.net

${ }^{+}$Present address: Marc Mußmann Division of Microbial Ecology, University of Vienna, Austria

Specialty section: This article was submitted to Extreme Microbiology, a section of the journal Frontiers in Microbiology

Received: 03 April 2016 Accepted: 03 June 2016

Published: 21 June 2016

Citation:

Winkel M, Salman-Carvalho V Woyke T, Richter M,

Schulz-Vogt HN, Flood BE, Bailey JV and Mußmann M (2016) Single-cell Sequencing of Thiomargarita Reveals Genomic Flexibility for Adaptation to Dynamic Redox Conditions.

Front. Microbiol. 7:964. doi: 10.3389/fmicb.2016.00964

\begin{abstract}
Matthias Winkel $1,2 *$, Verena Salman-Carvalho ${ }^{3}$, Tanja Woyke ${ }^{4}$, Michael Richter $^{5}$, Heide N. Schulz-Vogt ${ }^{6}$, Beverly E. Flood ${ }^{7}$, Jake V. Bailey ${ }^{7}$ and Marc Mußmann ${ }^{1 *+}$

1 Molecular Ecology Group, Department of Molecular Ecology, Max Planck Institute for Marine Microbiology, Bremen, Germany, ${ }^{2}$ Section Geomicrobiology, GFZ German Research Centre for Geoscience, Helmholtz Centre Potsdam, Potsdam, Germany, ${ }^{3}$ HGF MPG Joint Research Group for Deep-sea Ecology and Technology, Max Planck Institute for Marine Microbiology, Bremen, Germany, ${ }^{4}$ Department of Energy Joint Genome Institute, Walnut Creek, CA, USA, ${ }^{5}$ Microbial Genomics and Bioinformatics Group, Department of Molecular Ecology, Max Planck Institute for Marine Microbiology, Bremen, Germany, ${ }^{6}$ Leibniz-Institut für Ostseeforschung Warnemünde, Rostock, Germany, ${ }^{7}$ Department of Earth Sciences, University of Minnesota, Minneapolis, MN, USA
\end{abstract}

Large, colorless sulfur-oxidizing bacteria (LSB) of the family Beggiatoaceae form thick mats at sulfidic sediment surfaces, where they efficiently detoxify sulfide before it enters the water column. The genus Thiomargarita harbors the largest known freeliving bacteria with cell sizes of up to $750 \mu \mathrm{m}$ in diameter. In addition to their ability to oxidize reduced sulfur compounds, some Thiomargarita spp. are known to store large amounts of nitrate, phosphate and elemental sulfur internally. To date little is known about their energy yielding metabolic pathways, and how these pathways compare to other Beggiatoaceae. Here, we present a draft single-cell genome of a chain-forming "Candidatus Thiomargarita nelsonii Thio36", and conduct a comparative analysis to five draft and one full genome of other members of the Beggiatoaceae. "Ca. T. nelsonii Thio36" is able to respire nitrate to both ammonium and dinitrogen, which allows them to flexibly respond to environmental changes. Genes for sulfur oxidation and inorganic carbon fixation confirmed that "Ca. T. nelsonii Thio36" can function as a chemolithoautotroph. Carbon can be fixed via the Calvin-Benson-Bassham cycle, which is common among the Beggiatoaceae. In addition we found key genes of the reductive tricarboxylic acid cycle that point toward an alternative $\mathrm{CO}_{2}$ fixation pathway. Surprisingly, "Ca. T. nelsonii Thio36" also encodes key genes of the C2cycle that convert 2-phosphoglycolate to 3-phosphoglycerate during photorespiration in higher plants and cyanobacteria. Moreover, we identified a novel trait of a flavin-based energy bifurcation pathway coupled to a $\mathrm{Na}^{+}$-translocating membrane complex (Rnf). The coupling of these pathways may be key to surviving long periods of anoxia. As other Beggiatoaceae "Ca. T. nelsonii Thio36" encodes many genes similar to those of (filamentous) cyanobacteria. In summary, the genome of "Ca. T. nelsonii Thio36" provides additional insight into the ecology of giant sulfur-oxidizing bacteria, and reveals unique genomic features for the Thiomargarita lineage within the Beggiatoaceae.

Keywords: "Candidatus Thiomargarita nelsonii", single-cell genome, sulfur-oxidizing bacteria, cyanobacteria, multiple-displacement amplification, C2-cycle 


\section{INTRODUCTION}

Large colorless sulfur-oxidizing bacteria (LSB) are globally distributed and typically occur at the surface of sulfidic sediments. Here, opposed gradients of oxygen and sulfide (Jørgensen and Revsbech, 1983) favor the formation of dense populations of, e.g., Beggiatoa, Thioploca, and Thiomargarita (Jannasch et al., 1989; Fossing et al., 1995; Schulz et al., 1999). Both, marine and freshwater LSB oxidize various forms of reduced sulfur compounds (sulfide, thiosulfate, elemental sulfur), while some also use smaller organic compounds, such as acetate, lactate, and ethanol as energy source (Teske and Salman, 2014).

LSB commonly store elemental sulfur and typically occur as filaments or single cells within the top centimeters of the sediment. By their gliding or rolling motility, some LSB migrate between the deeper and surficial layers of the sediment, thereby bridging the gap between available electron donors and acceptors in the different sediment layers. In this manner, these LSB may gain a competitive advantage over other sulfur-oxidizing bacteria ( $\mathrm{SOB}$ ), which require a simultaneous access to both, electron donor and acceptor (Jørgensen and Gallardo, 1999). Sometimes, Thiomargarita and Beggiatoa co-exist in mats, which was attributed to a niche separation in these metabolically similar microorganisms (Grünke et al., 2011). While the ecological niches of LSB have been frequently studied (Teske and Salman, 2014 and reference therein), still little is known about how these distinct niches are reflected in the pan-genome of the Beggiatoaceae and even less is known about the genomes of the non-filamentous, mainly non-motile genus Thiomargarita.

Thiomargarita spp. were originally discovered in the upper most centimeters of an organic-rich diatomaceous ooze deposited beneath the Benguela upwelling system off the coast of Namibia (Schulz et al., 1999). The underlying sediments contain extremely high sulfide concentrations of up to $22 \mathrm{mM}$ (Brüchert et al., 2003). The enormous oxygen demand in this eutrophic and sulfidic system causes oxygen depletion in the sediment itself as well as in the overlying waters, and forces Thiomargarita to use electron acceptors other than oxygen. Nitrate is stored at $0.1-$ $0.8 \mathrm{M}$ concentrations in a large central vacuole that occupies $98 \%$ of the cell volume (Schulz et al., 1999). Also other members of the family Beggiatoaceae store nitrate in a central vacuole, and use it as alternative electron acceptor under anoxic conditions (Fossing et al., 1995; McHatton et al., 1996). Experimental evidence suggest that some freshwater and marine Beggiatoa spp. and Thioploca spp. perform dissimilatory reduction of nitrate to ammonium (Vargas and Strohl, 1985; McHatton et al., 1996; Otte et al., 1999), while other marine LSB perform denitrification (Sweerts et al., 1990; Mußmann et al., 2007; Beutler et al., 2012). A cryptic nitrogen cycle was even observed between denitrifiying marine Thioploca spp. filaments and their sheathassociated anaerobic ammonia-oxidizing (anammox) bacteria (Prokopenko et al., 2013). Another study showed the close association of marine Beggiatoa and aerobic ammonia-oxidizer to recycle nitrogen in highly fluctuating hydrothermal systems (Winkel et al., 2014). Besides genomic evidence for the different nitrate respiration pathways in LSB (Mußmann et al., 2007; MacGregor et al., 2013a), recent proteomic and transcriptomic analyses revealed the actual expression of denitrification genes in freshwater Thioploca ingrica (Kojima et al., 2015), and marine "Ca. Thiopilula sp." (Jones et al., 2015).

In addition to storing nitrate, many LSB also store polyphosphates and polymeric carbon. For example, Thiomargarita stores glycogen (Schulz and Schulz, 2005), while filamentous Beggiatoa species store polyhydroxyalcanoate as carbon and energy reserve (Brock and Schulz-Vogt, 2011).

In recent years, additional Thiomargarita ecotypes have been detected in various marine sediments worldwide, including methane seeps and hydrothermal systems (Kalanetra et al., 2005; Bailey et al., 2011; Grünke et al., 2011; Salman et al., 2011). Cells of this genus represent the largest free-living bacteria that are typically non-motile, spherical, and sometimes form chains surrounded by a thick mucus sheath (Schulz et al., 1999). Due to their apparent immobility, Thiomargarita are thought to depend on temporal variations in the chemical environment or on physical transport by traction currents, gas bubbles, or, in some cases, animal hosts.

Experimental approaches with the genus Thiomargarita are still sparse due to the lack of marine LSB cultivars and no genomic data is currently available. While LSB ecological habitats are governed by similar conditions, Thiomargarita physiological differentiates itself from its relatives by the lack of motility (Salman et al., 2013). In this study, we analyzed the genome of a single cell of the candidate species "Thiomargarita nelsonii" collected from the sediments off the coast of Namibia. Members of "Ca. T. nelsonii" were recently described to display the most diverse range of morphologies within the LSB, i.e., single freeliving spherical cells, unicells entrapped in empty diatom shells, or surrounded by an envelope structure, aggregates of reductively dividing, square-shaped cells, and attached living, elongated cells (Salman et al., 2013). The "Thiomargarita nelsonii" in this study was distinct from other morphotypes in that it forms distinctive, cylindrical shape cells often found in chains (Figure 1A).

We performed multiple displacement amplification (MDA) and genome sequencing of a single cell, " $\mathrm{Ca}$. T. nelsonii Thio36", and annotated the draft genome for comparison to six genomes of freshwater and marine Beggiatoaceae, including the unpublished genome Beggiatoa sp. strain '35Flor' (Winkel et al., in preparation) that was isolated from black-band diseased corals (Brock and Schulz-Vogt, 2011). We analyzed major pathways involved in energy, sulfur, carbon, phosphorus, and nitrogen metabolism in "Ca. T. nelsonii Thio36". As it has yet to be resolved whether Thiomargarita performs DNRA or denitrification, a special focus of this analysis was the nitrogen cycle.

\section{MATERIALS AND METHODS}

\section{Samples}

Sediment containing Thiomargarita cells were taken within the mud belt of the Benguela Upwelling System off the coast of Namibia across the coordinate block $21^{\circ} 1.01-25^{\circ} 30.00 \mathrm{~S}$ and $12^{\circ} 13.75-14^{\circ} 23.36 \mathrm{E}$ during the cruise M76 onboard the R/V Meteor (April 12th - May 13th, 2008). Sediment was retrieved 


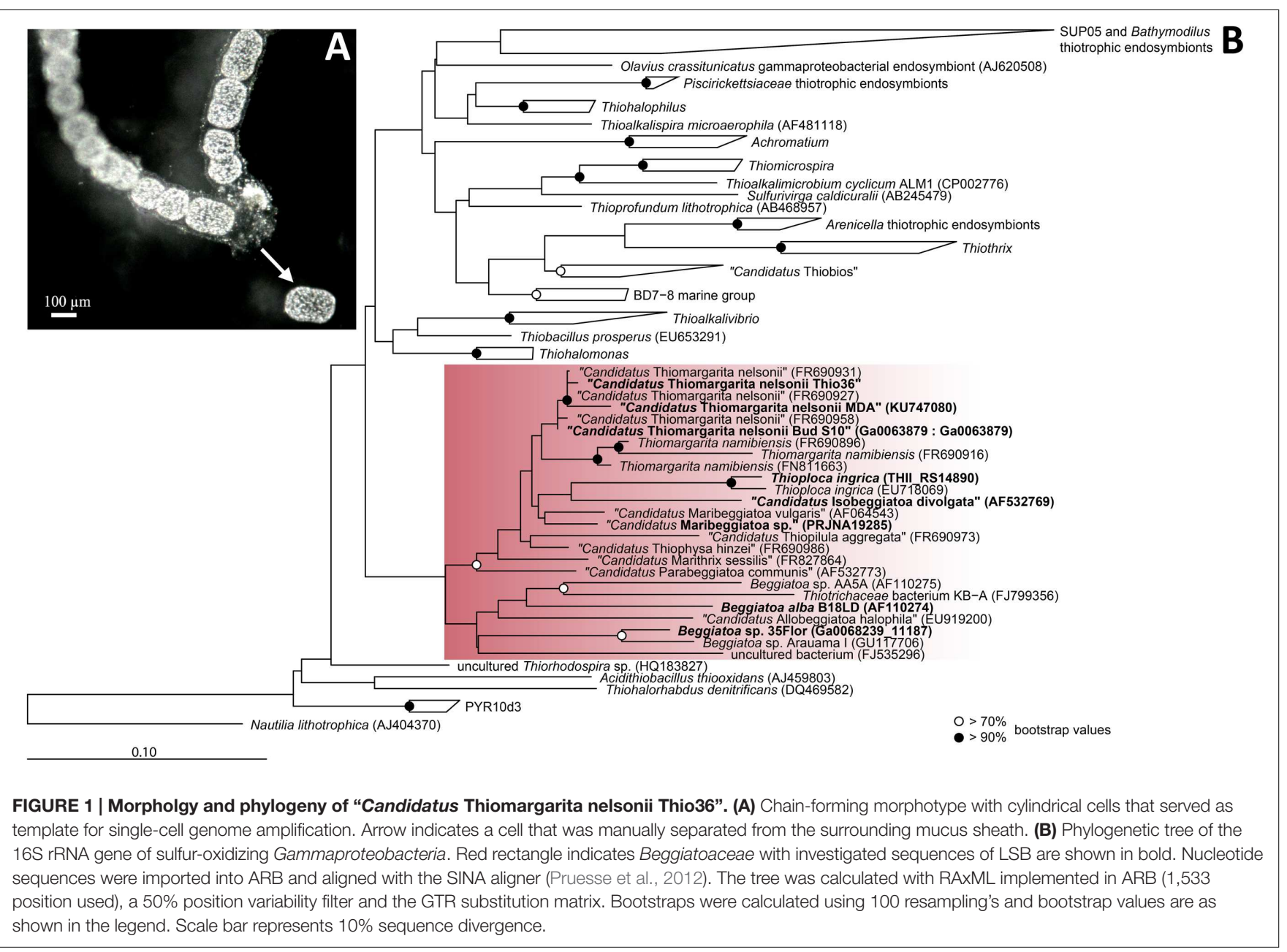

with a multicorer from water depths between 100 and $200 \mathrm{~m}$ across the coordinate block. The upper $3 \mathrm{~cm}$ of the sediments, which contained most of the Thiomargarita cells, were stored in closed plastic containers overlaid with bottom sea-water and kept at $4^{\circ} \mathrm{C}$.

\section{Separation of Single Cells}

Single cells with cylindrical shapes (Figure 1A) were separated from their external sheath under a stereo-microscope at a magnification of $20 \mathrm{x}$. The sheath was opened with two sterile needles and single cells were manually peeled out. The cells were clearly visible by their sulfur inclusions. Cells were carefully washed in autoclaved, sterile-filtered, $0.4 \%$ low-melting agarose (Lonza NuSieve, Basel, Switzerland) that was dissolved in seawater. We used wide-bored pipet tips to avoid cell damage. This procedure was repeated several times to remove potentially contaminating microorganisms and/or exogenous DNA. Cells were transferred onto Ampligrid slides (Advalytix, Olympus, Hamburg, Germany) that contained a hydrophilic central area surrounded by a hydrophobic ring, which allows amplification reactions in very small volumes to minimize contamination. Slides with single Thiomargarita cells were airdried and immediately processed or stored aseptically at $-20^{\circ} \mathrm{C}$.

\section{Single-cell MDA Reaction}

Multiple displacement amplification reactions of single cells were prepared under a PCR hood irradiated with UV-light to avoid contaminations with free DNA, plasmids, or DNA from human skin or breath. All used materials and chemicals were UV-light irradiated with the exception of the polymerase/primer mix. MDA reactions were performed with the Illustra GenomePhi V2 DNA amplification kit (GE Healthcare, Buckinghamshire, UK) as described previously (Jogler et al., 2011). MDA products were further diluted 1:100 and 1:1000 and assessed for potential contaminants by amplifying the 16S rRNA gene with different primer combinations targeting most bacteria (Supplementary Table S1). Furthermore, to verify the presence of Thiomargaritaspecific DNA, the partial intergenic transcribed spacer (ITS) region up/downstream between the $16 \mathrm{~S}$ and $23 \mathrm{~S}$ rRNA gene was amplified. For detailed PCR conditions see SI, and all used oligonucleotides are listed in Supplementary Table S1.

\section{Whole Genome Sequencing and Assembly}

The amplified genomic DNA from the single " $\mathrm{Ca}$. T. nelsonii Thio36" cell was sequenced at the Joint Genome Institute 
(Walnut Creek, CA, USA) using 2x 150 bp pair-end library on an Illumina HiSeq platform (Illumina Inc., San Diego, CA, USA) according to the manufacturer's protocol (Bennett, 2004). For quality control we used a sequence matching tool DUK with a kmer hashing method against the JGI in house artifact database, the human genome and typical MDA contaminations such as Delftia, Pseudomaonas, and Escherichia. After quality control and removal of redundant reads, the remaining reads were assembled with a combination of the Velvet (Zerbino and Birney, 2008) and Allpaths (Gnerre et al., 2010) assemblers. We predicted genes on the assembled contigs using Prodigal (Hyatt et al., 2010) and ran a BlastP and Megan analysis for taxonomic assignments. Created GC histograms were analyzed due to their different taxonomic levels down to subspecies. Based on a $7 \mathrm{Mbp}$ genome the estimated coverage was $>200 \mathrm{x}$. The assembled sequences have been deposited in the DDBJ/NCBI/EMBL databases (BioSample: SAMN04479841, accession no. LUTY00000000). The 16S rRNA gene sequence of the MDA product is deposited under the accession number KU747080.

\section{Gene Prediction, Annotation and Pathway Reconstruction of "Ca. T. nelsonii Thio36"}

Gene calling was performed by Glimmer3 for complete genes (Delcher et al., 2007), and MetaGene for partial genes (Noguchi et al., 2006). Ribosomal RNA gene sequences were predicted with the RNAmmer 1.2 software (Lagesen et al., 2007), and transfer RNAs were identified with tRNAscan-SE (Lowe and Eddy, 1997). The annotation was performed by a refined version of the GenDB v2.2 system (Meyer et al., 2003) supplemented by the java-based comparative analysis and search tool JCoast version 1.7 (Richter et al., 2008). Predicted ORFs were further verified via similarity searches against sequence databases NCBInr, Swiss-Prot, KEGG, COG, genomesDB (releases May 2013), and the protein family databases Pfam (release 27), and InterPro (release 42). Signal peptide predictions were verified by SignalP (Dyrløv Bendtsen et al., 2004), and transmembrane helixanalysis by TMHMM (Krogh et al., 2001). In parallel, predicted protein coding sequences were automatically annotated with MicHanThi (Quast, 2006). The MicHanThi software predicts gene functions based on similarity searches using the NCBI$\mathrm{nr}$ (including Swiss-Prot) and InterPro database. Pathways were manually reconstructed by comparison to published pathways in the Kyoto Encyclopedia of Genes and Genomes (KEGG) (Kanehisa and Goto, 2000). Predicted genes and pathways were further compared to automated annotations of the IMG/ER (Markowitz et al., 2012) platform. The IMG Genome ID is 2236661048 .

\section{Genome Completeness and Contamination Control}

The completeness of genomes was estimated based on tRNA counts compared to complete or nearly complete genomes of Beggiatoaceae. The number of tRNAs were 44, 46, and 47 for Beggiatoa alba (3 contigs), Thioploca ingrica (1 contig) and Beggiatoa leptomitiformis D-402 (1 contig) (Fomenkov et al.,
2015), respectively. A second estimation was based on 137 annotated single-copy genes that include all ribosomal proteins genes (Campbell et al., 2013). Testing for potential contaminants, we manually searched the dataset for additional tRNAs and 31 single-copy genes (Ciccarelli et al., 2006) using BLAST.

\section{Phylogenetic Analysis}

The nearly full length $16 \mathrm{~S}$ rRNA gene sequence (1,392 bp) was used for tree calculation with the ARB software package (Ludwig et al., 2004), where trees were calculated based on the database of the ARB-Silva release 111 (Quast et al., 2012) using a maximum likelihood algorithm (RaxML) and a 50\% base frequency filter. Subsequently, partial sequences were added to the reconstructed tree by the maximum parsimony algorithm without allowing changes in the overall tree topology. A multiple protein alignment of the ribulose-1,5-bisphosphate carboxylase/oxygenase large subunit form $1 \mathrm{Aq}(r b c L)$ was constructed with the integrated aligner of the ARB software tool, which was then manually refined. Phylogenetic tree reconstructions were performed with a maximum likelihood algorithm using the Dayhoff amino acid substitution matrix (Dayhoff et al., 1978) for evolutionary distance. A $75 \%$ base frequency and termini filter were applied considering 256 amino acid positions.

\section{RESULTS AND DISCUSSION}

\section{General Single-Cell Genome Features}

We successfully amplified and sequenced the draft genome of an individual Thiomargarita cell, allowing us to study the genomic potential of this uncultured bacterium. Mapping of raw reads against an artifact database, the human genome and typical MDA contaminants removed $1.7 \%$ of the reads. The reads assembled to 3,613 contigs and $5.3 \mathrm{Mb}$ of unique sequence information. The contig length ranged between $14.8 \mathrm{kbp}$ and $504 \mathrm{bp}$ with a N50 value of 1,835 bp. BlastP and Megan analysis showed highest similarity with Beggiatoa spp.. Based on the recovery of 25 tRNAs we estimated the genome completeness to be around $50-53 \%$ when compared to tRNAs numbers in genomes of Beggiatoa alba (46 tRNAs, 3 contigs), Beggiatoa leptomitiformis D-402 (47 tRNAs, 1 contig) and Thioploca ingrica (44 tRNAs, 1 contig). We identified 96 out of annotated 137 single-copy genes (Campbell et al., 2013) suggesting an even higher genome completeness of $70 \%$. The details of the "Ca. T. nelsonii Thio36" draft genome as well as those for other genomic datasets in our comparative analysis are listed in Table $\mathbf{1 .}$

\section{Screening for Contaminating DNA}

We confirmed the purity of the genome by PCR screening of 16S rRNA genes, as well as in silico examining genes only found in single copies using blastn and blastp analyses. Thiomargarita spp. have up to four self-splicing introns in their 16S rRNA gene (Salman et al., 2012), which facilitated the discrimination of the "Ca. T. nelsonii Thio36" 16S rRNA gene amplicons from potentially amplified contaminating DNA, as the elongated 16S rRNA gene would be discriminated against during universal PCR amplification (Salman et al., 2012). Thus, prior to genome 
TABLE 1 | General genome feature of the investigated LSB.

\begin{tabular}{|c|c|c|c|c|c|c|c|}
\hline genome feature & $\begin{array}{c}\text { “Ca. } \\
\text { Thiomargarita } \\
\text { nelsonii Thio36" }\end{array}$ & $\begin{array}{c}\text { "Ca. } \\
\text { Thiomargarita } \\
\text { nelsonii Bud S10" }\end{array}$ & $\begin{array}{c}\text { "Ca. } \\
\text { Isobeggiatoa } \\
\text { divolgata" }\end{array}$ & $\begin{array}{c}\text { "Ca. } \\
\text { Maribeggiatoa } \\
\text { sp." }\end{array}$ & $\begin{array}{l}\text { Beggiatoa sp. } \\
\text { 35Flor }\end{array}$ & $\begin{array}{l}\text { Beggiatoa } \\
\text { alba B18LD }\end{array}$ & $\begin{array}{c}\text { Thioploca } \\
\text { ingrica }\end{array}$ \\
\hline nucleotides & $5.3 \mathrm{Mb}$ & $6.2 \mathrm{Mb}$ & $7.6 \mathrm{Mb}$ & $4.8 \mathrm{Mb}$ & $4 \mathrm{Mb}$ & $4.3 \mathrm{Mb}$ & $4.8 \mathrm{Mb}$ \\
\hline contigs & 3,613 & 439 & 6,769 & 822 & 291 & 3 & 1 \\
\hline ORF & $7,596^{*}$ & 7,525 & 6,686 & 5,258 & 3,552 & 3,665 & 3,964 \\
\hline coding percentage & 72 & 82 & 57 & 85 & 87 & 86 & 86 \\
\hline max. contig length & $14 \mathrm{~kb}$ & $190 \mathrm{~kb}$ & $19 \mathrm{~kb}$ & $71 \mathrm{~kb}$ & 138 kb & $500 \mathrm{~kb}$ & $4.8 \mathrm{Mb}$ \\
\hline tRNAs & 23 & 46 & 45 & 46 & 38 & 46 & 44 \\
\hline GC content [\%] & 42 & 41.3 & 38.5 & 38.2 & 38.5 & 40 & 41.2 \\
\hline $\begin{array}{l}\text { proteins of known } \\
\text { function }\end{array}$ & 3,486 & 4,310 & 3,414 & 2,962 & 2,746 & 2,867 & 2,788 \\
\hline $\begin{array}{l}\text { conserved hypothetical } \\
\text { proteins }\end{array}$ & 967 & n.d. & 1046 & 619 & 380 & 377 & n.d. \\
\hline hypothetical proteins & 3143 & n.d. & 2226 & 1677 & 426 & 421 & n.d. \\
\hline $\begin{array}{l}\text { genome completeness } \\
\text { (\%) based on } 137 \\
\text { SCG }^{\dagger}\end{array}$ & 70 & 89.8 & 98.5 & 98.5 & 97.8 & 100 & 100 \\
\hline reference & this study & Flood et al., 2016 & $\begin{array}{l}\text { Mußmann et al., } \\
2007\end{array}$ & $\begin{array}{l}\text { MacGregor et al., } \\
2013 b\end{array}$ & $\begin{array}{l}\text { IMG Genome ID } \\
2606217769\end{array}$ & $\begin{array}{c}\text { BioProject } \\
\text { PRJNA224116 }\end{array}$ & $\begin{array}{c}\text { Kojima et al., } \\
2015\end{array}$ \\
\hline
\end{tabular}

* Likely overestimation due to high number of frame shifts. n.d., not determined. `Based on 137 annotated single-copy genes (SCG) (Campbell et al., 2013).

sequencing of the single-cell MDA product, we performed a PCR using universal bacterial 16S rRNA primers (Supplementary Table S1), and retrieved a single product of the expected size of $\sim 2,300$ bp (Salman et al., 2012). The 16S rRNA gene of the single-cell genome $(1,392 \mathrm{bp}$, without the intron of $128 \mathrm{bp})$ clustered phylogenetically with other 16S rRNA sequences of “Ca. T. nelsonii", sharing 99.1-100\% sequence identity with this species cluster (Figure 1B). The recovery of 31 single-copy genes including ribosomal proteins and others, plus $\operatorname{Sec} G, \operatorname{HrcA}$, RimM, and PNPase showed highest similarity to " $\mathrm{Ca}$. T. nelsonii Bud S10" (Supplementary Table S2) and other Beggiatoaceae. Consistent with this, 4,062 ORFs (of a total of 7,596) displayed best BLAST hits to Gammaproteobacteria. All our results point at a contamination-free amplified genome of " $\mathrm{Ca}$. T. nelsonii Thio36".

\section{Phylogenetic Affiliation}

The genus Thiomargarita belongs to the Beggiatoaceae, a family within the Gammaproteobacteria, and encompasses three species, of which two have only recently been proposed as Candidatus species (Salman et al., 2011). In the genome of " $\mathrm{Ca}$. T. nelsonii Thio36", we detected a nearly complete $16 \mathrm{~S}$ rRNA gene that contained an intron (S1369) at the expected position for " $\mathrm{Ca}$. T. nelsonii” (Salman et al., 2012). The 16S rRNA gene without intron sequence was used for phylogenetic tree reconstructions, and affiliated with 99.1-100\% nucleotide identity to the cluster of other " $\mathrm{Ca}$. T. nelsonii" sequences including other chain-forming morphotypes (Salman et al., 2011; Figure 1B).

To further analyze the relatedness to other LSB we compared the "Ca. T. nelsonii Thio36" dataset with the draft genome of " $\mathrm{Ca}$. I. divolgata” (Mußmann et al., 2007) and tested for reciprocal best match (RBM) hits. The two genomes shared 471 open reading frames (ORFs) (cut off $\mathrm{e}^{-05}, 65 \%$ alignment coverage). Usually, the expected number of RBM hits among genomes of different genera of a family is significantly higher, however, here the considerably lower numbers might be caused by the fact that a large amount of genes are only partially presented in the draft genome datasets.

\section{Genes of Potentially Cyanobacterial Origin}

A total of 626 genes had best blastp hits to cyanobacterial genes, which is consistent with previous studies of LSB genomes (Mußmann et al., 2007; MacGregor et al., 2013c; Flood et al., 2014). For example, the ' $\mathrm{Ca}$. T. nelsonii Thio36' genome encodes $x i s H$ and $x i s I$ genes (Supplementary Table S3), which are required in cyanobacteria for the heterocyst-specific rearrangement of the FdxN element as part of the nitrogenase operon (Ramaswamy et al., 1997). The FdxN element is also encoded in the genomes of ' $\mathrm{Ca}$. T. nelsonii Thio36', 'Ca. Maribeggiatoa sp., and ' $\mathrm{Ca}$. I. divolgata' (data not shown). Almost all genes with sequence identities higher than $70 \%$ were flanked by Beggiatoaceae genes, while the GC content varies between 30.1 and $55.4 \%$ (Supplementary Table S3), all of which further indicates a substantial horizontal gene transfer between ancestors of LSB and cyanobacteria (Mußmann et al., 2007; MacGregor et al., 2013c).

\section{Nitrogen Metabolism}

The "Ca. T. nelsonii Thio36" genome encodes genes for the reduction of nitrate via DNRA and denitrification pathway. We identified two dissimilatory nitrate reductases (nar and nap), and an assimilatory nitrate reductase (nasA) (Figure 2 and Supplementary Table S4). The membrane-bound (nar) catalyzes the first step of nitrate-reduction in the denitrification pathway, while the periplasmic (nap) dissimilatory nitrate reductase catalyzes the same reaction for the denitrification and 

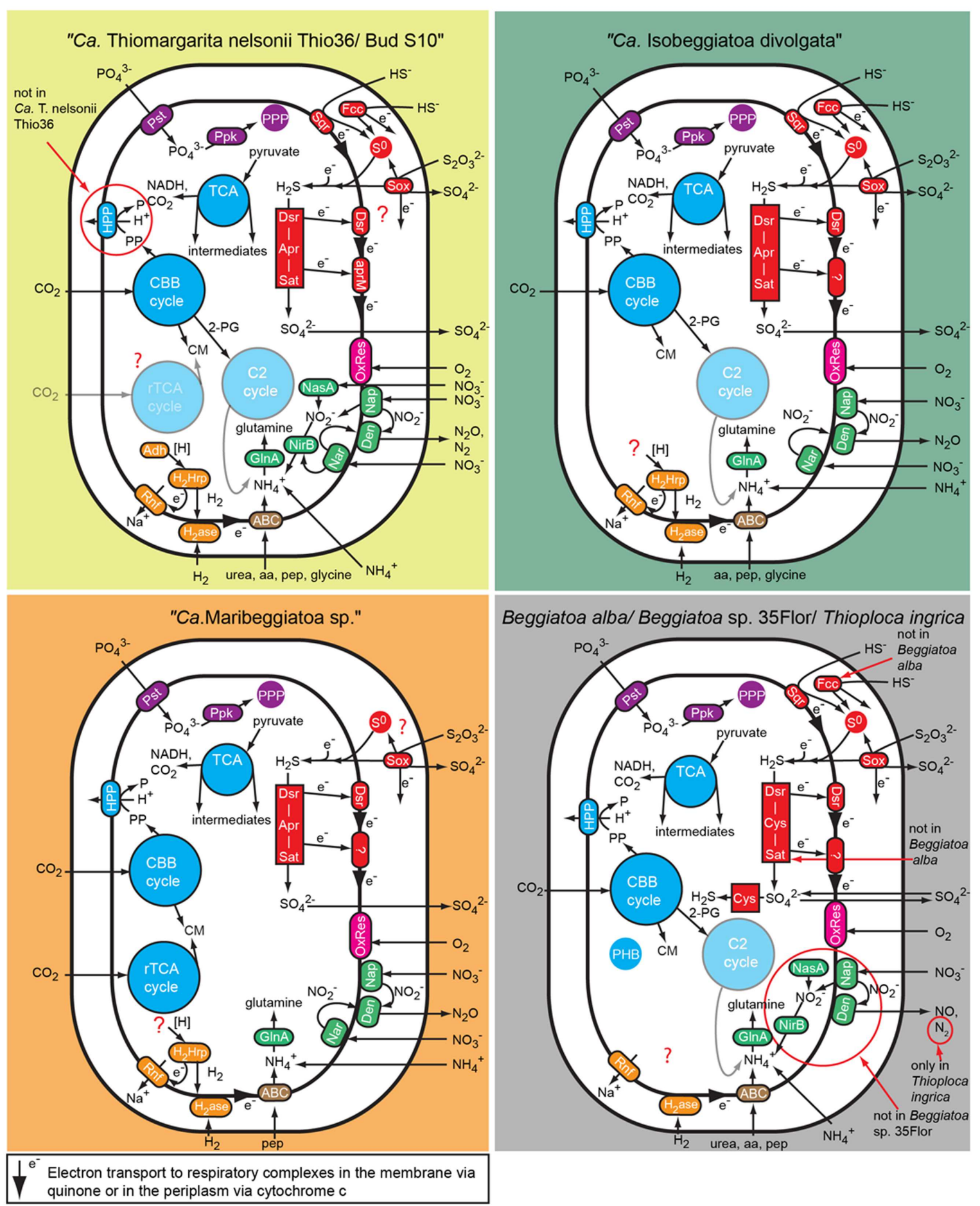

FIGURE 2 | Comparison of C, N, S, P, and energy pathways in the investigated large, colorless LSB based on the genomic information. Note that not all genes essential for some of the predicted pathways have been found in the genomes because of the fragmented nature of most genomes. Aa, amino acid; $\mathrm{ABC}$, ABC transporter; Adh, alcohol dehydrogenase; Apr, APS reductase; CBB cycle, Calvin-Benson-Basshman cycle; C2 cycle, glyoxylate cycle; CM, cell material; Cys, $3^{\prime \prime}$ phosphoadenylylsulfate reductase; Den, denitrification proteins; Dsr, dissimilatory sulfite reductase and related proteins; Fcc, flavocyctochrome c; GlnA, Glutamine synthetase; $\mathrm{H}_{2}$ ase, uptake hydrogenase; $\mathrm{H}_{2} \mathrm{Hrp}$, methyl viologen-reducing hydrogenase:heterodisulfide reductase complex; HPP, proton translocating pyrophosphatase; Nar, membrane-bound respiratory nitrate reductase; Nap, periplasmatic respiratory nitrate reductase; NasA, assimilatory nitrate reductase; NirB, assimilatory and dissimilatory nitrite reductase; OxRes, oxygen respiration; pep, peptides; PHB, polyhydroxybutyrate granule; PPP, polyphosphate granule; Ppk, polyphosphate kinase; Pst, phosphate transport system; Rnf, membrane-bound electron transport complex; rTCA, reductive tricarboxylic acid cycle; $\mathrm{S}^{0}$, sulfur globules; Sat, ATP sulfurylase; Sox, SOX enzyme complex; Sqr, sulfide quinone reductase; TCA, tricarboxylic acid cycle. 
DNRA pathway (Moreno-Vivián et al., 1999; Morozkina and Zvyagilskaya, 2007). Both dissimilatory nitrate reductase genes are also present in "Ca. I. divolgata" (Mußmann et al., 2007), in "Ca. T. nelsonii Bud S10" (Flood et al., 2016) as well as in "Ca. Maribeggiatoa sp." (MacGregor et al., 2013b), whereas the genome of Beggiatoa alba B18LD only encodes the periplasmic enzyme (Figure 2 and Supplementary Table S4). The cytoplasmic assimilatory nitrate reductase (nasA) is also found in Beggiatoa alba B18LD, Thioploca ingrica, and "Ca. T. nelsonii Bud S10" together with a nitrite reductase (nirBD) involved in both the assimilatory and dissimilatory pathway. In combination with the assimilatory nitrate reductase (nasA), these two enzymes assimilate ammonium (Figure 2; Table 2), as was shown for endosymbiontic $\mathrm{SOB}$ of the vesicomyid clams and Bathymodiolus sp. mussels (Kleiner et al., 2012a). In "Ca. T. nelsonii Thio36", "Ca. T. nelsonii Bud S10", T. ingrica and B. alba B18LD, the nitrite reductase could be used to respire nitrite via DNRA
(Figure 2; Table 2 and Supplementary Table S4), which has been experimentally demonstrated for B. alba (Vargas and Strohl, 1985). In contrast, the genomes of marine Beggiatoa lack both nas $A$ and nirBD. Instead, they encode a multiheme cytochrome with nitrite reductase function (MacGregor et al., 2013b), which may be involved in DNRA (Klotz et al., 2008; Hawley et al., 2014; Jones et al., 2015). For a more detailed description see SI.

Genes encoding the nitrite reductase (nirSCF) for denitrification are also present in " $\mathrm{Ca}$. T. nelsonii Thio36", "Ca. T. nelsonii Bud S10", T. ingrica and "Ca. I. divolgata". Furthermore, "Ca. T. nelsonii Thio36", "Ca. T. nelsonii Bud S10", T. ingrica, "Ca. I. divolgata", and "Ca. Maribeggiatoa sp." encode a membrane-bound nitric oxide reductase (nor). Together with the earlier described periplasmic nitrate reductase and the multiheme cytochrome with nitrite reductase-function, all five organisms have the genetic potential to denitrify nitrate to nitrous oxide (Figure 2 and Supplementary Table S4).

TABLE 2 | Energy conservation and metabolic pathways in the investigated LSB.

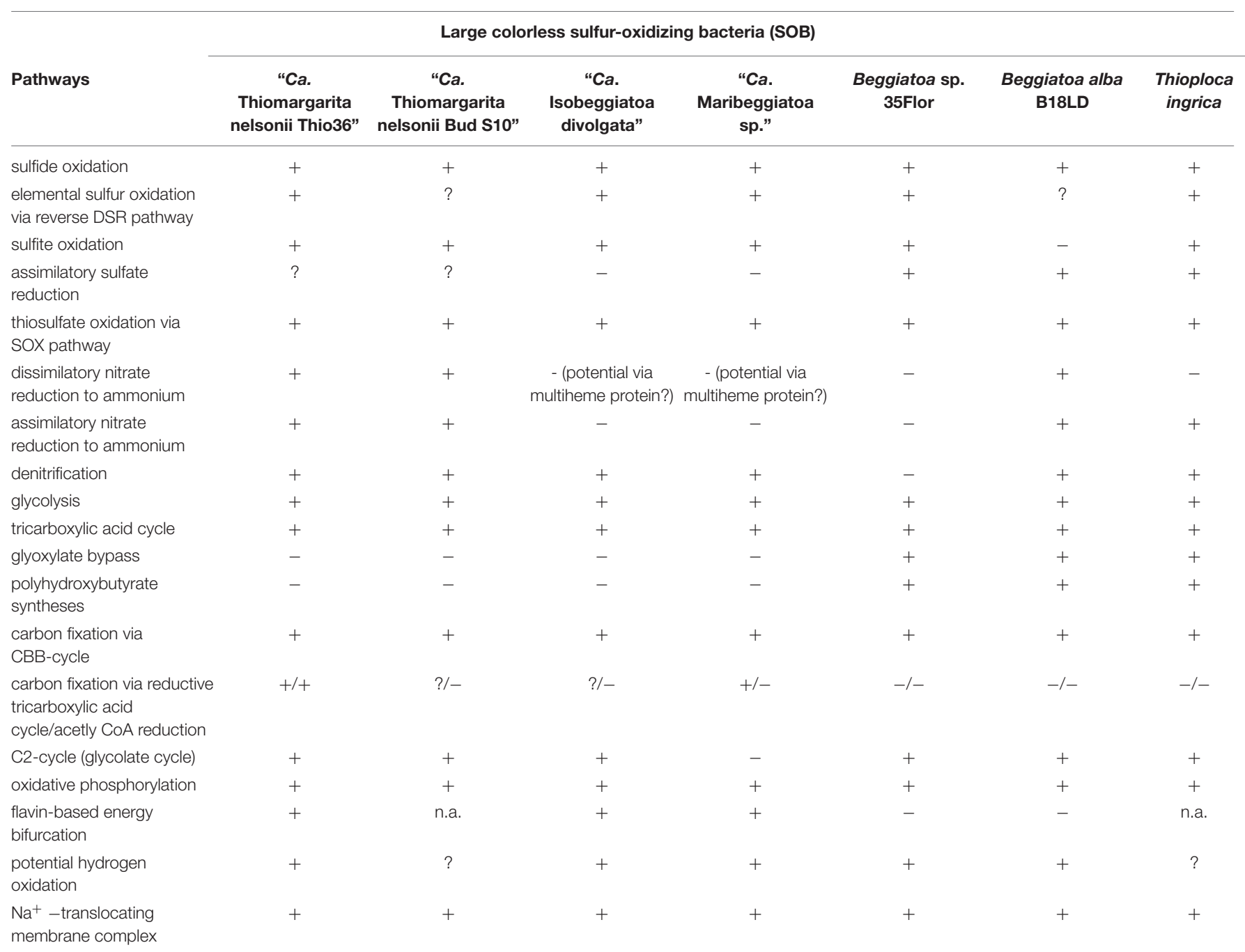

+ complete set of genes for metabolic pathway encoded. ? no complete set of genes for pathway or pathway with alternative genes. - genes of pathway not found or not encoded. n.a., not analyzed. 
Interestingly, we also found genes for the nitrous oxide reductase (nosZD) (Supplementary Table S4) in "Ca. T. nelsonii Thio36", "Ca. T. nelsonii Bud S10", and T. ingrica. Accordingly, a completely functioning denitrification pathway to dinitrogen in all these organisms is possible (Figure $\mathbf{2}$ and Supplementary Table S4). Thus, “Ca. T. nelsonii Thio36” may gain energy via both nitrate reduction pathways, DNRA and denitrification. We speculate that the alternate use of these two pathways is determined by the fluctuating redox conditions in the highly dynamic habitat of Thiomargarita. Thus, a differential expression pattern may be controlled by external environmental conditions as shown before (Kraft et al., 2014), realized here within one cell instead of within a whole community. For a detailed description of the genes involved in nitrogen metabolism see supplementary information.

The draft genome of strain Beggiatoa sp. 35Flor lacks all necessary genes for DNRA and denitrification, which is in line with experimental data. This strain rather uses internally stored sulfur for anaerobic respiration (Schwedt et al., 2012).

\section{Carbon Metabolism Glycolysis}

The "Ca. T. nelsonii Thio36" genome encodes a nearly complete glycolysis pathway, while it lacks a glucose-6-phosphate isomerase, a trait shared with the "Ca. T. nelsonii Bud S10" genome (Supplementary Table S4). This gene was found in all other LSB, therefore it might either be encoded in the missing section of the two " $\mathrm{Ca}$. T. nelsonii" genomes, or represent a true deletion. "Ca. T. nelsonii Thio36" encodes a polyphosphate glucokinase instead of the ATP glucokinase, which is typical of microorganisms that accumulate polyphosphate (Tanaka et al., 2003). Thus, there is genetic evidence for the observation that T. namibiensis accumulates polyphosphate granules (Schulz and Schulz, 2005). All other LSB contain a complete glycolysis pathway with " $\mathrm{Ca}$. I. divolgata", T. ingrica and " $\mathrm{Ca}$. Maribeggiatoa sp.” also processing polyphosphate-dependent glucokinase. So far, cultured freshwater LSB have not been shown to grow on sugars and other complex organic substrates, but they can use acetate as a carbon and energy source (Teske and Salman, 2014).

\section{Tricarboxylic Acid Cycle (TCA) and Glyoxylate Bypass}

“Ca. T. nelsonii Thio36" encodes a complete tricarboxylic acid cycle (TCA) cycle, consistent with most other LSB (Table 2 and Supplementary Table S4). A complete TCA cycle is not common among lithotrophic organisms, such as sulfur oxidizers, because they are often obligate autotrophs (Teske and Salman, 2014). In particular, the presence of a complete alpha ketoglutarate dehydrogenase-complex is unusual, as the lack of this complex has been used as an indicator for obligate autotrophy (Wood et al., 2004).

The glyoxylate-cycle uses five enzymes of the TCA cycle (citrate synthase, aconitase, succinate dehydrogenase, fumarase, malate dehydrogenase) to form succinate and glyoxylate from isocitrate for gluconeogenesis in organisms growing on 1- or 2-C compounds such as acetate. The essential genes encoding malate synthase and isocitrate lyase (Walsh and Koshland, 1984) were so far only detected in the genomes of the marine Beggiatoa sp. strain 35Flor and in the freshwater LSB T. ingrica and B. alba B18LD (Table 2 and Supplementary Table S4). This confirmed earlier experimental studies suggestive of a functional glyoxylate bypass with the freshwater Beggiatoa sp. strains OH-75-B (Nelson and Castenholz, 1981) and D-402 (Stepanova et al., 2002). Moreover, all LSB with the exception of " $\mathrm{Ca}$. Maribeggiatoa sp." encode an acetyl-CoA synthethase to activate acetate, which may serve as a potential energy and carbon source. This is in line with the proposed mixotrophic lifestyle of Thiomargarita namibiensis (Schulz and de Beer, 2002; Beutler et al., 2012) based on the observation that it may use organic carbon such as acetate as carbon source, but not as energy source. Accordingly, the reverse TCA (rTCA) could be utilized by Thiomargarita spp. to transform inorganic carbon into biomass, as is discussed below.

\section{Carbon Fixation Pathways Calvin-Benson-Bassham (CBB) Cycle}

The key enzyme of carbon fixation via the CBB-cycle is the ribulose-1,6-bisphosphate carboxylase/oxygenase (RuBiscCO), which was initially detected in a marine Beggiatoa sp. (Nelson and Jannasch, 1983). The genomes of "Ca. T. nelsonii Thio36", "Ca. I. divolgata”, T. ingrica and B. alba B18LD encode RuBisCO form I, while "Ca. Maribeggiatoa sp.", "Ca. T. nelsonii Bud S10" and Beggiatoa sp. strain 35Flor encode RuBisCO form II (Figure 3 and Supplementary Table S4). It is known that other SOB express different forms of this enzyme (Kleiner et al., 2012a) with distinct affinities for $\mathrm{CO}_{2}$ and $\mathrm{O}_{2}$ (Badger and Bek, 2008). We also identified most genes of the CBB-cycle in " $\mathrm{Ca}$. T. nelsonii Thio36" with the exception of the sedoheptulase1,7-bisphophatase and the fructose-1,6-bisphosphatase. Instead, a 6-phosphofructokinase was present (Supplementary Table S4), which contains pyrophosphate-binding sites similar to a pyrophosphate-dependent 6-phosphofructokinase (Reshetnikov et al., 2008). This enzyme is proposed to have a tri-function replacing the missing enzymes sedoheptulase-1,7-bisphophatase, the fructose-1,6-bisphosphatase as well as a phosphoribulose kinase (Kleiner et al., 2012b). A possible involvement in additional carbon fixation was proposed (see Supplementary Information). The genome of " $\mathrm{Ca}$. T. nelsonii Thio36" also lacks a ribose-5-phosphate isomerase, which is likely due to the incompleteness of the assembled genome. This enzyme is encoded in all other LSB (Supplementary Table S4).

It is interesting that although " $\mathrm{Ca}$. T. nelsonii Thio36" and "Bud S10" belong to the same Thiomargarita species they contain two different types of RubisCO enzymes. The two strains thrive in extremely different habitats, which could be a determining factor for this different adaptation. "Ca. T. nelsonii Thio36" lives in coastal sediments influenced by the decay of diatomrich phytodetritus from surface waters that are dependent on the upwelling of nutrient-rich bottom waters. Here, upwelling intensity, and thus phytodetrial flux to the sediments, is seasonal and dissolved $\mathrm{CO}_{2}$ may be less bioavailable under periods of low nutrient input promoting a need for a more discriminatory RuBisCO type I. On the contrary, "Ca. T. nelsonii Bud S10" lives in dense microbial mats in deep-sea sediments above a 


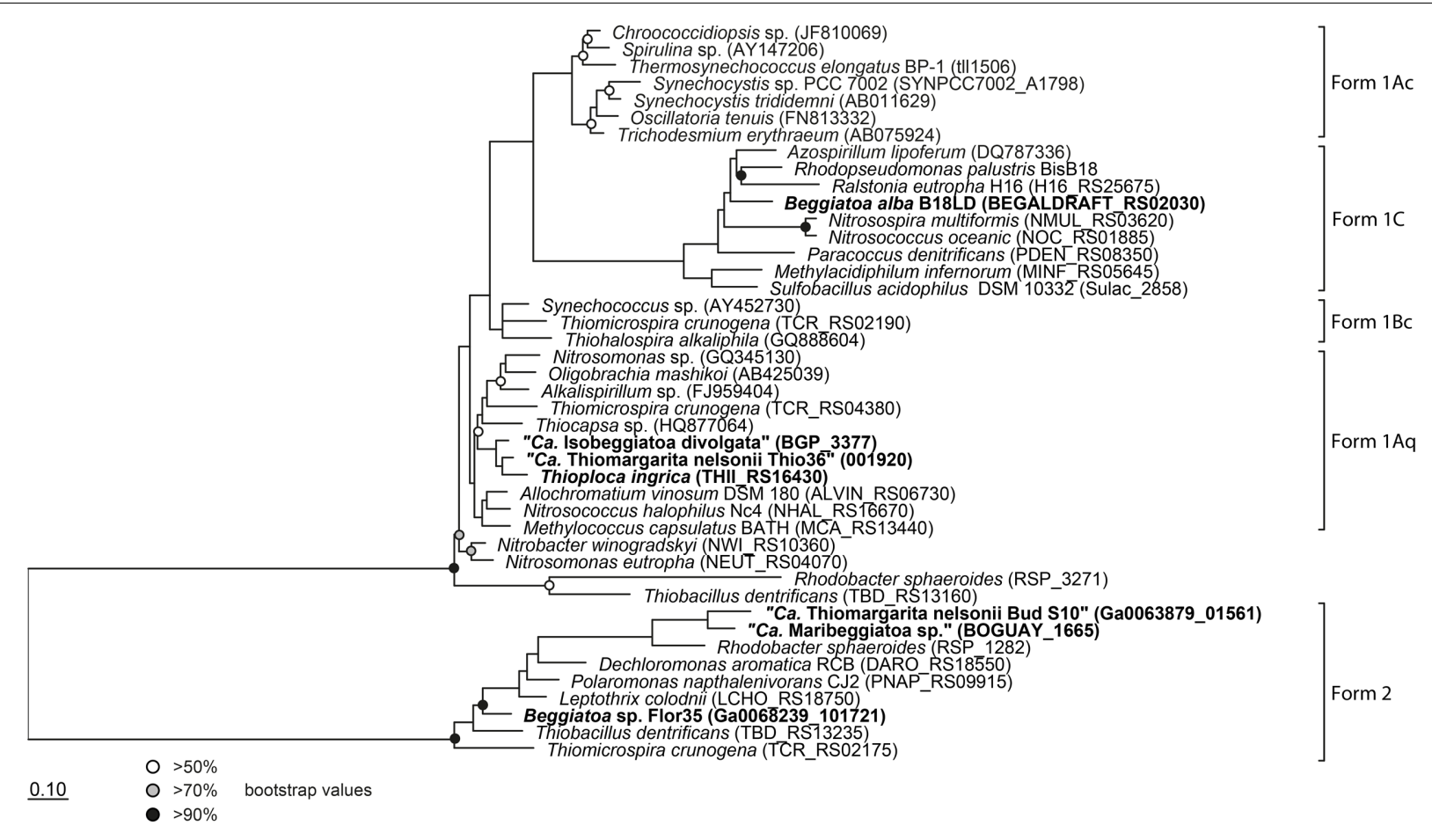

FIGURE 3 | Phylogenetic tree of the large subunit of the ribulose-1,5-bisphosphate carboxylase/oxygenase (RubisCo). All investigated LSB contain the gene and are shown in bold. Protein sequences were imported into ARB and aligned with the integrated aligner. The tree was calculated with RAxML implemented in ARB (256 positions used) and bootstraps were calculated using 100 resampling's. Scale bar represents $10 \%$ sequence divergence.

cold seep system. These sediments are strongly influenced by constantly advecting methane-rich fluids that stimulate high rates of anaerobic methane oxidation and respiration of sulfate (Treude et al., 2003). Under these conditions, $\mathrm{CO}_{2}$ generated via respiration is likely to be high while oxygen levels consistently lower, thus favoring a form II RuBisCO.

\section{Oxygenase-Activity of RuBisCO and a Potential Glycolate Cycle}

Atmospheric oxygen concentrations stimulates growth in Thiomargarita spp. (Schulz, 2006), and the production of the 2-phosphoglycolate (2-PG) by the oxygenase activity of RuBisCO can be expected. Since 2-PG is an inhibitor of the CBB-cycle it needs to be removed for a proper functioning of the $\mathrm{CBB}$ cycle. In higher plants this is carried out by the photorespiratory metabolism (Bauwe et al., 2012), which converts the 2-PG into 3-phosphoglycerate (3-PG) and shuttles it back into the CBB cycle. An active 2-PG metabolism (C2-cycle) that converts 2-PG and shuffles it back into the Calvin-cycle has been demonstrated for the unicellular cyanobacterium Synechocystis sp. strain PCC 6803 (Eisenhut et al., 2008). Other earlier observations in the serine biosynthesis pathway of the methanotrophic Methylococcus capsulatus (Bath) proposed a similar pathway to the C2-cycle of higher plants (Taylor et al., 1981; Ward et al., 2004). The role for such a C2-cyle in microorganisms using RuBisCO for carbon fixation is not clear. Nevertheless, the genome of "Ca. T. nelsonii Thio36" encodes an almost complete set of genes that are involved in the C2-cycle (Supplementary
Table S4). While the only missing gene is the essential class-III glycerate kinase (GLYK) producing 3-PG, however, we found genes that can convert the photorespiratory intermediate serine via a phosphorylation to phosphoserine and produce 3-PG in an alternative way (Supplementary Table S4; Figure 4). Homologs of the C2 cycle genes were also detected in other LSB, with the exception of " $\mathrm{Ca}$. Maribeggiatoa sp.", which lacks a glycolate oxidase (Figure 4 and Supplementary Table S4). For a detailed description see Supplementary Information.

\section{Reductive Tricarboxylic Acid (rTCA)}

Until now, only the sulfur-oxidizing endosymbiont " $\mathrm{Ca}$. Endoriftia persephone" of the hydrothermal tubeworm Riftia pachyptila has been shown to encode both the CBB- and the rTCA-cycle for $\mathrm{CO}_{2}$ fixation, and expresses them under different conditions (Markert et al., 2007). Besides the CBB-cycle we also found genes encoding a potentially complete rTCA in the genome of "Ca. T. nelsonii Thio36" (Supplementary Table S4). We found a gene that showed $>70 \%$ sequence identity to the ATP-citrate lyase of " $\mathrm{Ca}$. E. persephone" alpha subunit, which is a key enzyme for the rTCA. This gene is also present in the genome of "Ca. Maribeggiatoa sp." (MacGregor et al., 2013b), but the beta subunit of the ATP-citrate lyase cannot be found, so it is not clear if the enzyme is functional. Nevertheless, we found other genes indicative for the rTCA, such as 2-oxoglutarate:ferredoxin oxidoreductase (kor $A B)$, and the fumarate reductase large subunit $(f r d A)$. These genes are present in the genomes of “Ca. T. nelsonii Thio36", “Ca. T. nelsonii Bud S10", “Ca. I. 


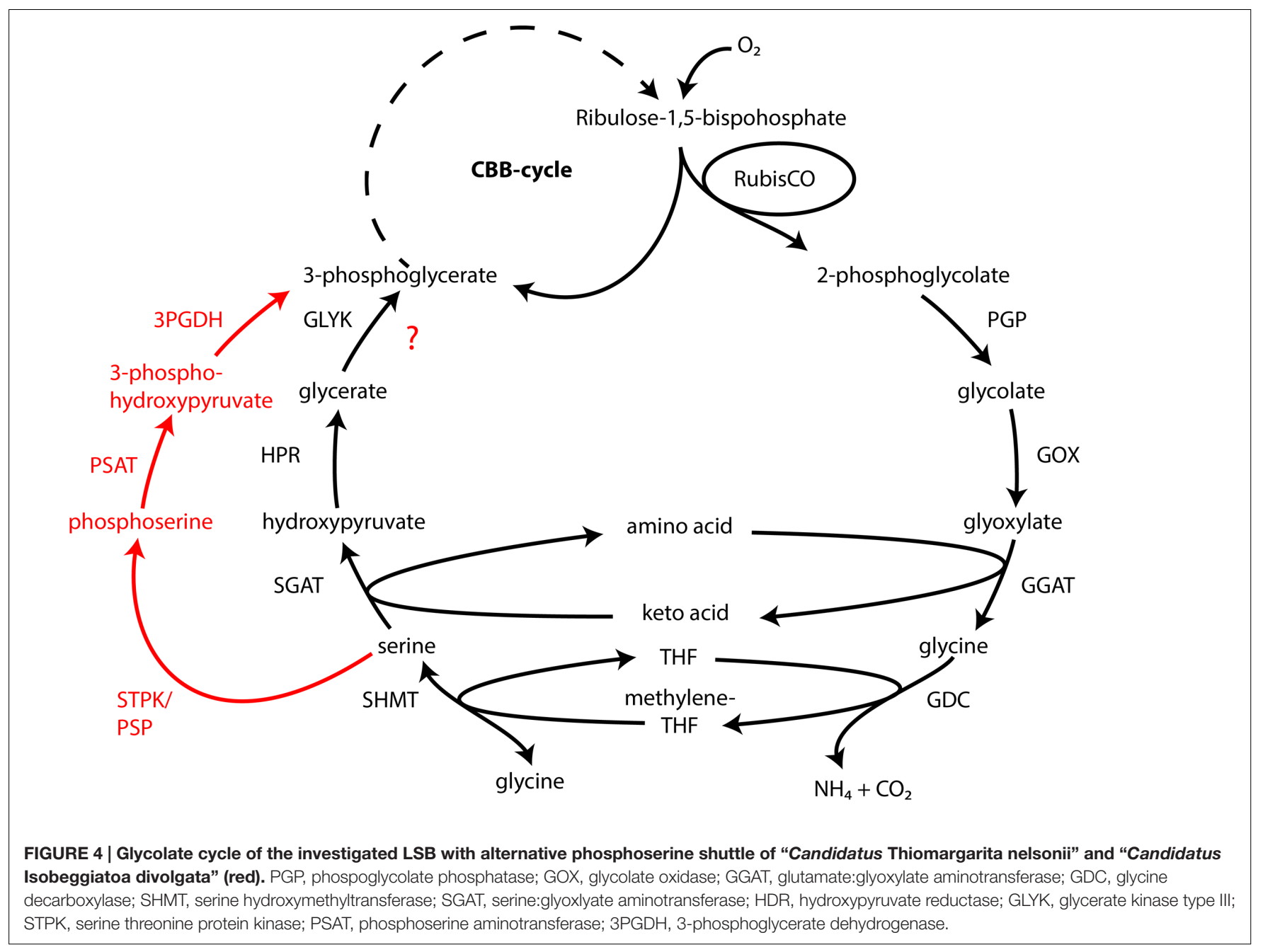

divolgata”, and “Ca. Maribeggiatoa sp.” “Ca. T. nelsonii Thio36” may further convert the produced acetyl-CoA through the ATP citrate lyase to fix two more molecules of $\mathrm{CO}_{2}$ (Evans et al., 1966) (Supplementary Table S4). The encoded enzymes for this pathway are pyruvate:ferredoxin oxidoreductase (por $A B G D)$, phosphoenolpyruvate synthase ( $p p s A)$, and ATP-dependent phosphenolpyruvate carboxykinase ( $p c k A)$. Accordingly, "Ca. T. nelsonii Thio36" and "Ca. Maribeggiatoa sp." might be additional examples of $\mathrm{SOB}$ that are capable of fixing carbon by two distinct $\mathrm{CO}_{2}$ fixation pathways, but this interpretation should be confirmed through additional experiments.

\section{Energy Metabolism}

\section{Sulfur and Hydrogen Oxidation}

We found only a subset of genes known to be encoded by LSB genomes necessary for the metabolism of reduced sulfur compounds (Table 2). Likely, this is the result of the incomplete nature of the genome. The sulfide:quinone oxidoreductase (sqr) is present in all genomes, while an alternative enzyme, the flavocytochrome c sulfide dehydrogenase $(f c c A B)$, is also encoded with both subunits in all genomes with the exception of B. alba B18LD (Figure 2; Supplementary Table S4). The occurrence of two different enzymes for the same substrate, sulfide, points toward tightly regulated sulfide oxidation under different environmental conditions in these organisms. LSB oxidize sulfide to sulfur that is stored in the periplasm by a yet unknown process (Dahl et al., 2008), and is visible as bright white globules in all analyzed LSB (Figure 1A) (Mezzino et al., 1984; Mußmann et al., 2007; Salman et al., 2011; Schwedt et al., 2012; MacGregor et al., 2013b).

We also found an incomplete set of genes for the reverse dissimilatory sulfite reductase (rDSR) pathway, and the thiosulfate-oxidizing Sox-pathway. The set of genes for these pathways are nearly complete in the genomes of " $\mathrm{Ca}$. I. divolgata", T. ingrica, Beggiatoa sp. 35Flor, "Ca. Maribeggiatoa sp.”, and "Ca. T. nelsonii Bud S10" (Figure 2 and Supplementary Table S4). For a more detailed description of the localization of genes involved in the sulfur cycle see Supplementary Information.

Recently, an aerobic-type, uptake $[\mathrm{Ni}, \mathrm{Fe}]$ hydrogenase was found actively oxidizing hydrogen in the endosymbiontic SOB of the hydrothermal vent mussel Bathymodiolus (Petersen et al., 2011). The same type of hydrogenase is encoded by " $\mathrm{Ca}$. T. nelsonii Thio36" and almost all other LSB genomes. For detailed analysis of hydrogenase genes in LSB see (Kreutzmann, 
2013). Accordingly, the potential for hydrogen oxidation seems to be more widespread among SOB than previously expected. While hydrogen has been showed to serve as an alternative energy source in the Beggiatoa sp. strain 35Flor (Kreutzmann and Schulz-Vogt, 2016), it has yet to be tested in other LSB.

\section{Oxidative Phosphorylation}

Non-photosynthetic SOB usually couple the oxidation of inorganic sulfur compounds or organic carbon (e.g., acetate) to the transport of electrons during oxidative phosphorylation to produce a proton motive force for energy production in the form of ATP. Oxidative phosphorylation has been demonstrated experimentally for freshwater and marine Beggiatoa strains (Strohl et al., 1986; Prince et al., 1988).

Genes for all five complexes of the respiratory electron transport chain are present in the genome of " $\mathrm{Ca}$. T. nelsonii Thio36" and all other LSB (Table 2; Supplementary Table S4). All genomes encoded the NADH dehydrogenase I (nouABCDEFGHIJKLMN), but the genes for the subunits were typically scattered over several operons due to the fragmented nature of most datasets. "Ca. T. nelsonii Thio36", lacks the genes nouABC, and Beggiatoa sp. strain 35Flor lacks the gene nouE (Supplementary Table S4). The membrane-associated succinate dehydrogenase complex II ( $s d h A B C D)$ is present in all genomes, while homologs for the membrane anchor $(s d h D)$ cannot be detected in "Ca. T. nelsonii Thio36", T. ingrica and "Ca. Maribeggiatoa sp.". The third complex is encoded by genes for the ubiquinol-cytochrome $c$ reductase, and a similar operon $($ pet $A B C)$ is present in all genomes. Only in "Ca. I. divolgata", the pet $C$ gene is located on a different contig than the petAB genes (Supplementary Table S4). Several different complex IV-associated genes were found in the genomes. While the cytochrome c oxidase cbb3-type (ccoNOQP, high oxygen affinity) is present in all genomes (Supplementary Table S4), we only detected the cytochrome coxidase aa3-type ( $\operatorname{cox} C B A$, low oxygen affinity) in the genomes of " $\mathrm{Ca}$. T. nelsonii Thio36" and " $\mathrm{Ca}$. I. divolgata” (Supplementary Table S4). This was unexpected, because the activity of a cytochrome c oxidase aa3-type has been reported for the freshwater strain Beggiatoa leptomitiformis D402 (Muntyan et al., 2005). In the genomes of " $\mathrm{Ca}$. T. nelsonii Bud S10 and Thio36", B. alba B18LD and "Ca. Maribeggiatoa sp." we found a third complex, a cytochrome d ubiquinol oxidase $(c y d A B)$ (Supplementary Table S4). All genomes encode the F-type ATPase (atpCDGAHFEB), while we find homologs of vacuolar (V)-type ATPase (ntpABCDEFGHIK) only in the marine LSB (Supplementary Table S4). The F-type ATPase is involved in ATP synthesis at the cytoplasmic membrane, while the V-type ATPase is used to hydrolyse ATP at the vacuolar membrane to facilitate ion-translocations (Mußmann et al., 2007; Beutler et al., 2012). The latter may be a specific feature for the large vacuolated marine SOB of the family Beggiatoaceae.

\section{Heterodisulfide and Flavin-based Electron Bifurcation}

Homologous genes for a heterodisulfide reductase ( $h d r A B C)$ involved in energy metabolism have been intensely studied in methanogens (Thauer et al., 2008) and sulfate-reducing Deltaproteobacteria (Haveman et al., 2003; Strittmatter et al., 2009), and were found in "Ca. T. nelsonii Thio36". Methanogens use $\mathrm{Hdr}$ in a complex with a coupled methyl viologen-reducing hydrogenase $(\mathrm{Mvh})$ to reduce a coenzyme during methanogenesis (Thauer et al., 2008). We identified a homologous Mvh in " $\mathrm{Ca}$. T. nelsonii Thio36", but it is organized in a different operon, suggesting a decoupling of the gene functions. The role of such a decoupled complex in SOB is unclear. But there is evidence that the heterodisulfide reductase is involved in sulfur oxidation, since it was up-regulated in the proteome of the sulfuroxidizing endosymbiont " $\mathrm{Ca}$. Endoriftia persephone" under sulfur-rich conditions (Markert et al., 2007). Interestingly, both genes had best blast hits to Geobacter spp. with identities between 34 to $48 \%$, and occur in a similar operon (Supplementary Figures S1 and S2). The heterodisulfide reductase function in Geobacter spp. is so far not known (Coppi, 2005).

"Ca. T. nelsonii Thio36" encodes other heterodisulfide reductase genes ( $h d r D E F)$. $H d r D E$ genes occur in methanogens with cytochromes, where these membrane-bound enzymes, together with a hydrogenase (vhoACG), reduce the CoM-SS-CoB complex, similar to methanogens without cytochromes (Thauer et al., 2008). It was unusual that neither of the two enzymes contained transmembrane domains, but both had two typical iron-sulfur binding sites $\left(\mathrm{CX}_{2} \mathrm{CX}_{2} \mathrm{CX}_{3} \mathrm{C}\right)$ and the $h d r E$ heme binding site $\left(\mathrm{CX}_{2} \mathrm{CH}\right)$. The function of the $h d r F$ gene, which encodes a heterodisulfide oxidoreductase with a $\mathrm{NAD}(\mathrm{P}) \mathrm{H}$ subunit is unclear. The same sequence and operon structure of the $h d r D E F$ genes was also found in the genome of "Ca. Maribeggiatoa sp." and "Ca. T. nelsonii Bud S10", while upstream of the complex we found a methyl viologenreducing hydrogenase delta subunit $(m v h D)$ together with two genes that code for the heterodisulfide reductase alpha subunit ( $h d r A$ ) (Supplementary Figure S1 and Supplementary Table S4). Interestingly, upstream of the $h d r A$ genes is a gene encoding a fumarate reductase/succinate dehydrogenase $(f d r A / s d h A)$, which might be a coupling to membrane-bound electron transport. The latter combination is also present in the genome of "Ca. T. nelsonii Thio36" (Supplementary Figure S1).

The FAD-containing iron-sulfur protein $h d r A$ is of special interest. It uses ferredoxin as electron acceptor and can be coupled to a ferredoxin-oxidizing $\mathrm{Na}^{+}$-translocating membrane complex in a so called flavin-based electron bifurcation (FBEB) pathway (Buckel and Thauer, 2013). Strikingly, all genomes of the large, colorless SOB have genes for a full $\mathrm{Na}^{+}$translocating RnfABCDGE membrane complex that oxidizes ferredoxin and reduces $\mathrm{NAD}^{+}$(Biegel et al., 2011) (Figure 5; Table 2 and Supplementary Table S4). Therefore, a FBEB process could be used by them and "Ca. T. nelsonii Thio36" under long-term anoxic conditions in sulfidic waters or during migration of motile LSB such as " $\mathrm{Ca}$. I. divolgata" and " $\mathrm{C} a$. Maribeggiatoa sp." into deeper anoxic sediment layers at times when their internal electron acceptor nitrate is used up. 


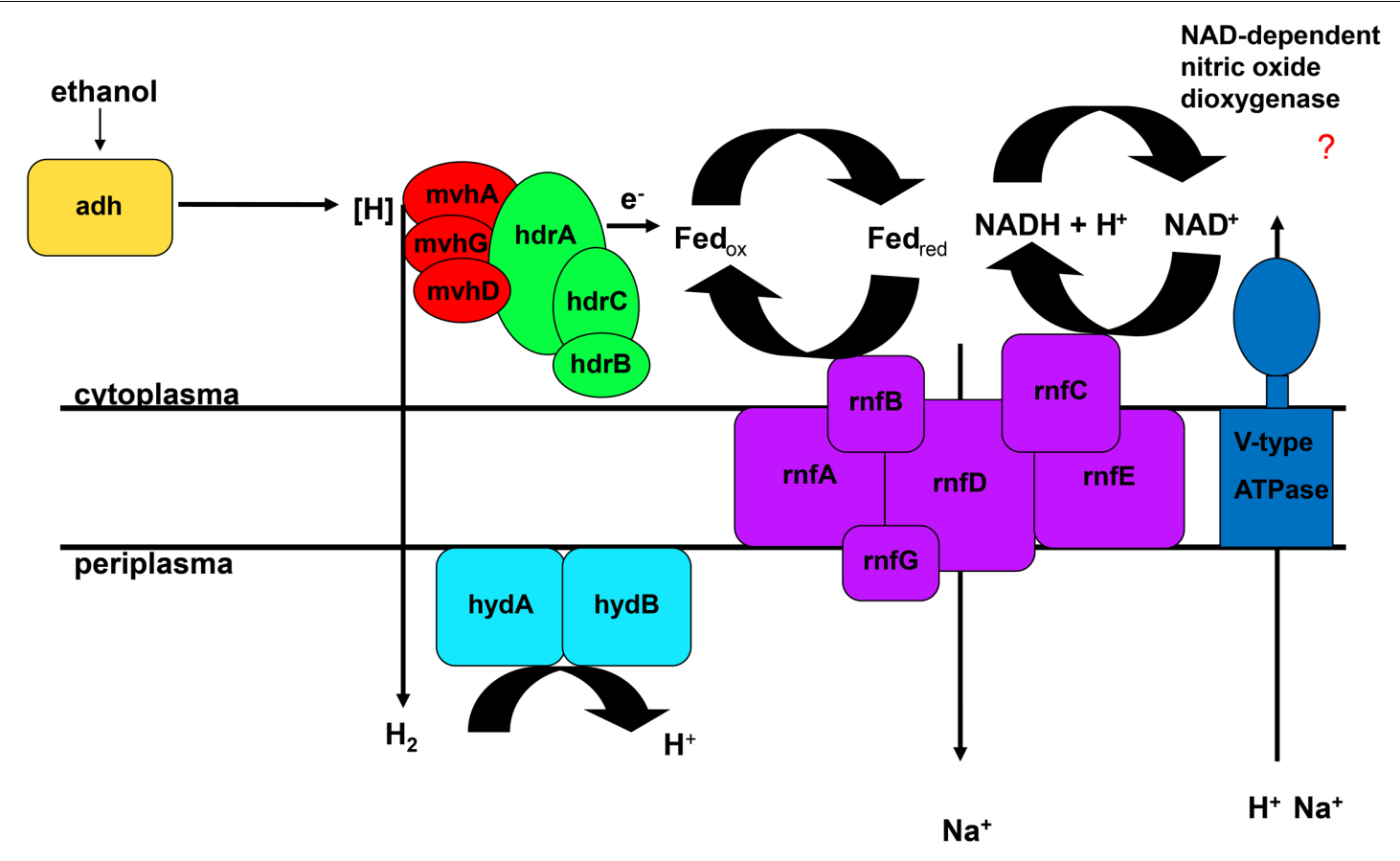

FIGURE 5 | Flavin-based electron bifurcation coupled to ethanol oxidation. Adh, alcohol dehydrogenase; hdr, heterodisulfide reductase; hyd, periplasmatic hydrogenase; mvh, methyl viologen-reducing hydrogenase; rnf, membrane-bound electron transport complex.

The genome of "Ca. T. nelsonii Thio36" also contains other periplasmic hydrogenases involved in energy metabolism. The periplasmic-located nickel-dependent hydrogenase $(h y d A B)$ was found in SRB and is up-regulated during ethanol oxidation in Desulfovibrio vulgaris (Haveman et al., 2003). In SRB they are proposed to be involved in hydrogen cycling between the cytoplasm and periplasm, whereby the alcohol dehydrogenase (adh) transfers hydrogen to the Hdr:Mvh-complex which produces molecular hydrogen. This is further transferred directly to the periplasmic hydrogenase $h y d A B$ by a yet unidentified membrane complex, converting it back to protons and producing a proton motive force (Haveman et al., 2003). Thus, the coupling of FBEB and hydrogen cycling would result in the higher proton/ $\mathrm{Na}^{+}$ion motive force (Figure 5). Interestingly, we also found a gene encoding an $a d h$ in the genome of " $\mathrm{Ca}$. T. nelsonii Thio36", thus alcohol oxidation coupled to FBEB might be possible. Homologs for both hydAB and adh genes are not found in any other genome of the LSB (Supplementary Table S4). So far, it is not clear whether a coupling of these pathways is possible under long-term anoxic conditions, or, which substrates are involved directly or indirectly, such as ethanol, hydrogen etc. Further physiological experiments are needed to clarify, whether enzymatic reactions are similar to those of methanogens, SRB or acetogens (Buckel and Thauer, 2013) are possible in LSB.

In line with the dual nitrate reduction and possiblly dual carbon fixation pathways identified here, the identification of multiple alternate pathways for energy conservation in Thiomargarita may reflect their adaptation to a non-motile lifestyle in a highly fluctuating environment with reoccurring, but, dynamic changes of redox potentials and nutrient supplies. The adaptation with a broad genetic repertoire appears to be a survival strategy in Thiomargarita, and, to a certain extent, also in the other LSB.

\section{Intracellular Storage}

It is well documented that at least some LSB can store several organic and inorganic compounds as granules in the periplasm, in the cytoplasm, or dissolved in the central vacuole (Schulz and Schulz, 2005; Brock and Schulz-Vogt, 2011; Teske and Salman, 2014). In all analyzed LSB we found a complete set of genes for the uptake of inorganic phosphate and the production of polyphosphate. The production of organic storage compounds in the form of polyhydroxybutyrate (PHB) was only found in T. ingrica, B. alba B18LD, and Beggiatoa sp. strain 35Flor (Figure 2), which all also encode the glyoxylate bypass to use acetate as an additional carbon source. Further details are described in the Supplementary Information.

\section{CONCLUSION}

Thiomargarita species occur globally and are involved in biogeochemical cycles that are important for ecosystem functioning. Despite their conspicuous size and general sulfuroxidizing characteristics little is known about their genetic potential. Here, we present the genomic features of a single-cell of "Ca. Thiomargarita nelsonii Thio36" and its potential for chemolithotrophy, carbon assimilation, energy metabolism and storage of nutrients. 
The genomic comparison of " $\mathrm{Ca}$. T. nelsonii Thio36" to the other large colorless SOB showed that they share a large number of metabolic capabilities such as the complete TCA cycle and glycolysis, carbon fixation via the CBB-cycle, energy conservation via the oxidative phosphorylation, sulfide oxidation, polyphosphate syntheses, potential hydrogen oxidation, and $\mathrm{Na}^{+}$-translocating membrane complexes (Table 2). Separating the genus Thiomargarita from other members of the family, however, was the trait that the two " $\mathrm{Ca}$. T. nelsonii" genomes often encode dual mechanisms to convert substrates. This might be a special adaptation to a non-motile lifestyle, yet, thriving in an environment with rapidly changing redox conditions. They possess two nitrate reduction pathways, the $\mathrm{CBB}$ and potentially the rTCA carbon fixation pathways, and versatile oxidative metabolisms involving different reduced sulfur compounds, hydrogen and even organic molecules. Moreover, the "Ca. T. nelsonii Thio36" genome contains a new, only recently proposed energy conserving pathway known as FBEB for surviving anaerobic conditions under the absence of suitable electron acceptors for respiration of $\mathrm{H}_{2}$. This metabolic feature could be relevant in facultative anaerobic strains exposed to long-term sulfidic conditions in the environment, as it can provide enough energy for ATP generation. Interestingly, phylogenetically closely-related LSB, such as the two sequenced "Ca. T. nelsonii" cells (Figure 1B), show partially different sets of functional genes, e.g., types of $\mathrm{RuBisCO}$ (Figure 3), that point toward divergent evolutionary developments during the adaptation to different environmental niches.

A high degree of sequence similarity between genes from LSB to those in filamentous cyanobacteria has been demonstrated (Mußmann et al., 2007; MacGregor et al., 2013c; Flood et al., 2014), and includes the genomes of " $\mathrm{Ca}$. T. nelsonii" as shown in our study (Supplementary Table S3). This further supports early and extensive horizontal gene transfer between ancestors of these groups. However, a modern coexistence of cyanobacteria and Thiomargarita spp. has so far never been reported, unlike the often encountered co-inhabitation of microbial mats by filamentous cyanobacteria and other LSB (Teske and Salman, 2014).

The here presented data on the metabolic potential of " $\mathrm{Ca}$. T. nelsonii" based on the first insights into the genomes of the genus Thiomargarita opens a large window of opportunity for hypothesis-driven ecophysiological experiments. These days, a suite of culture-independent methods is available that can be used to study LSB. Metatranscriptomic and -proteomics approaches may shed light on LSB communities reacting to changes in their environment as exemplified in (Jones et al., 2015, 2016), and single-cell approaches such as mRNA FISH or nano-SIMS could be used with these easily identifiable cells to monitor the

\section{REFERENCES}

Badger, M. R., and Bek, E. J. (2008). Multiple Rubisco forms in proteobacteria: their functional significance in relation to $\mathrm{CO}_{2}$ acquisition by the CBB cycle. J. Exp. Bot. 59, 1525-1541. doi: 10.1093/jxb/erm297

Bailey, J. V., Salman, V., Rouse, G. W., Schulz-Vogt, H. N., Levin, L. A., and Orphan, V. J. (2011). Dimorphism in methane seep-dwelling ecotypes of the largest known bacteria. ISME J. 5, 1926-1935. doi: 10.1038/ismej.2011.66 differential expression of alternative pathways and the differential incorporation of external resources.

\section{AUTHOR CONTRIBUTIONS}

MW, VS-C, and MM conceived of this study. HNS collected samples. MW and VS-C extracted the single cell from the sheath and removed contaminants. MW performed the DNA extraction and PCR screening of the single-cell Thiomargarita samples. TW performed the Illumina DNA sequencing and read assembly, TW, and MR performed the genome annotation. MW analyzed the sequence data with the assistance of MR and MM. MW performed phylogenic analyses, BEF and JVB performed the assembly of the Bud S10 genome. MW wrote the manuscript with input from all authors. All authors read and approved the final version of the manuscript.

\section{FUNDING}

We would like to thank the Max Planck Society and the DOI Joint Genome Institute for financial support. The Thiomargaritacontaining sediment sample was collected as part of the Meteor cruise M76 funded by the German Research Society through 'DFG Em 37/30-1'. The work conducted by the US Department of Energy Joint Genome Institute, a DOE Office of Science User Facility, is supported under Contract No. DE-AC02-05CH11231. VS-C was supported by the Deutsche Forschungsgemeinschaft grant Sa2505/1-1.

\section{ACKNOWLEDGMENTS}

We thank Lynne Goodwin and the JGI team for excellent support within the framework of the GEBA project. We also thank Manuel Kleiner, Anne-Christin Kreutzmann, and Anne Schwedt for fruitful discussions and early comments on the manuscript. We would like to thank Emil S. Ruff for comments on an early version of the manuscript. We are grateful to Rudolf Amann for the excellent and continuous support. This study was funded by the Max Planck Society, Germany.

\section{SUPPLEMENTARY MATERIAL}

The Supplementary Material for this article can be found online at: http://journal.frontiersin.org/article/10.3389/fmicb. 2016.00964

Bauwe, H., Hagemann, M., Kern, R., and Timm, S. (2012). Photorespiration has a dual origin and manifold links to central metabolism. Curr. Opin. Plant Biol. 15, 269-275. doi: 10.1016/j.pbi.2012. 01.008

Bennett, S. (2004). Solexa Ltd. Pharmacogenomics 5, 433-438. doi: 10.1517/14622416.5.4.433

Beutler, M., Milucka, J., Hinck, S., Schreiber, F., Brock, J., Mußmann, M., et al. (2012). Vacuolar respiration of nitrate coupled to energy conservation 
in filamentous Beggiatoaceae. Environ. Microbiol. 14, 2911-2919. doi: 10.1111/j.1462-2920.2012.02851.x

Biegel, E., Schmidt, S., González, J. M., and Müller, V. (2011). Biochemistry, evolution and physiological function of the Rnf complex, a novel ion-motive electron transport complex in prokaryotes. Cell. Mol. Life Sci. 68, 613-634. doi: 10.1007/s00018-010-0555-8

Brock, J., and Schulz-Vogt, H. N. (2011). Sulfide induces phosphate release from polyphosphate in cultures of a marine Beggiatoa strain. ISME J. 5, 497-506. doi: 10.1038/ismej.2010.135

Brüchert, V., Jørgensen, B. B., Neumann, K., Riechmann, D., Schlösser, M., and Schulz, H. (2003). Regulation of bacterial sulfate reduction and hydrogen sulfide fluxes in the central Namibian coastal upwelling zone. Geochim. Cosmochim. Acta 67, 4505-4518. doi: 10.1016/S0016-7037(03)00275-8

Buckel, W., and Thauer, R. K. (2013). Energy conservation via electron bifurcating ferredoxin reduction and proton/ $\mathrm{Na}^{+}$translocating ferredoxin oxidation. Biochim. Biophys. Acta 1827, 94-113. doi: 10.1016/j.bbabio.2012. 07.002

Campbell, J. H., O’Donoghue, P., Campbell, A. G., Schwientek, P., Sczyrba, A., Woyke, T., et al. (2013). UGA is an additional glycine codon in uncultured SR1 bacteria from the human microbiota. Proc. Natl. Acad. Sci. U.S.A 110, 5540-5545. doi: 10.1073/pnas.1303090110

Ciccarelli, F. D., Doerks, T., von Mering, C., Creevey, C. J., Snel, B., and Bork, P. (2006). Toward automatic reconstruction of a highly resolved tree of life. Science 311, 1283-1287. doi: 10.1126/science.1123061

Coppi, M. V. (2005). The hydrogenases of Geobacter sulfurreducens: a comparative genomic perspective. Microbiology 151, 1239-1254. doi: 10.1099/mic.0.27535-0

Dahl, C., Friedrich, C., and Kletzin, A. (2008). "Sulfur oxidation in prokaryotes," in eLS (New York, NY: John Wiley \& Sons).

Dayhoff, M. O., Schwartz, R., and Orcutt, B. C. (1978). "Chapter 22: A model of evolutionary change in proteins," in Atlas of Protein Sequences and Structure, ed. M. O. Dayhoff (Washington, DC: National Biomedical Research Foundation), 345-352.

Delcher, A. L., Bratke, K. A., Powers, E. C., and Salzberg, S. L. (2007). Identifying bacterial genes and endosymbiont DNA with Glimmer. Bioinformatics 23, 673-679. doi: 10.1093/bioinformatics/btm009

Dyrløv Bendtsen, J., Nielsen, H., von Heijne, G., and Brunak, S. (2004). Improved prediction of signal peptides: SignalP 3.0. J. Mol. Biol. 340, 783-795. doi: 10.1016/j.jmb.2004.05.028

Eisenhut, M., Ruth, W., Haimovich, M., Bauwe, H., Kaplan, A., and Hagemann, M. (2008). The photorespiratory glycolate metabolism is essential for cyanobacteria and might have been conveyed endosymbiontically to plants. Proc. Natl. Acad. Sci. U.S.A. 105, 17199-17204. doi: 10.1073/pnas.0807043105

Evans, M. C., Buchanan, B. B., and Arnon, D. I. (1966). A new ferredoxindependent carbon reduction cycle in a photosynthetic bacterium. Proc. Natl. Acad. Sci. U.S.A. 55, 928-934. doi: 10.1073/pnas.55.4.928

Flood, B. E., Bailey, J. V., and Biddle, J. F. (2014). Horizontal gene transfer and the rock record: comparative genomics of phylogenetically distant bacteria that induce wrinkle structure formation in modern sediments. Geobiology 12, 119-132. doi: 10.1111/gbi.12072

Flood, B. E., Fliss, P., Jones, D. S., Dick, G. J., Jain, S., Kaster, A.K., et al. (2016). Single-cell (Meta-)genomics of a dimorphic Candidatus Thiomargarita nelsonii reveals genomic plasticity. Front. Microbiol. 7:603. doi: 10.3389/fmicb.2016.00603

Fomenkov, A., Vincze, T., Grabovich, M. Y., Dubinina, G., Orlova, M., Belousova, E., et al. (2015). Complete genome sequence of the freshwater colorless sulfur bacterium Beggiatoa leptomitiformis neotype strain D-402T. Genome Announc. 3:e1436-15. doi: 10.1128/genomeA.01436-15

Fossing, H., Gallardo, V. A., Jørgensen, B. B., Huttel, M., Nielsen, L. P., Schulz, H., et al. (1995). Concentration and transport of nitrate by the mat-forming sulphur bacterium Thioploca. Nature 374, 713-715. doi: 10.1038/374713a0

Gnerre, S., MacCallum, I., Przybylski, D., Ribeiro, F. J., Burton, J. N., Walker, B. J., et al. (2010). High-quality draft assemblies of mammalian genomes from massively parallel sequence data. Proc. Natl. Acad. Sci. U.S.A. 108, 1513-1518. doi: 10.1073/pnas.1017351108

Grünke, S., Felden, J., Lichtschlag, A., Girnth, A.-C., De Beer, D., Wenzhöfer, F., et al. (2011). Niche differentiation among mat-forming, sulfide-oxidizing bacteria at cold seeps of the Nile Deep Sea Fan (Eastern Mediterranean Sea). Geobiology 9, 330-348. doi: 10.1111/j.1472-4669.2011.00281.x
Haveman, S. A., Brunelle, V., Voordouw, J. K., Voordouw, G., Heidelberg, J. F., and Rabus, R. (2003). Gene expression analysis of energy metabolism mutants of Desulfovibrio vulgaris Hildenborough indicates an important role for alcohol dehydrogenase. J. Bacteriol. 185, 4345-4353. doi: 10.1128/JB.185.15.43454353.2003

Hawley, A. K., Brewer, H. M., Norbeck, A. D., Paša-Tolić, L., and Hallam, S. J. (2014). Metaproteomics reveals differential modes of metabolic coupling among ubiquitous oxygen minimum zone microbes. Proc. Natl. Acad. Sci. U.S.A. 111, 11395-11400. doi: 10.1073/pnas.1322132111

Hyatt, D., Chen, G.-L., LoCascio, P. F., Land, M. L., Larimer, F. W., and Hauser, L. J. (2010). Prodigal: prokaryotic gene recognition and translation initiation site identification. BMC Bioinformatics 11:119. doi: 10.1186/1471-210511-119

Jannasch, H. W., Nelson, D. C., and Wirsen, C. O. (1989). Massive natural occurrence of unusually large bacteria (Beggiatoa sp.) at a hydrothermal deepsea vent site. Nature 342, 834-836. doi: 10.1038/342834a0

Jogler, C., Wanner, G., Kolinko, S., Niebler, M., Amann, R., Petersen, N., et al. (2011). Conservation of proteobacterial magnetosome genes and structures in an uncultivated member of the deep-branching Nitrospira phylum. Proc. Natl. Acad. Sci. U.S.A. 108, 1134-1139. doi: 10.1073/pnas.1012694108

Jones, D. S., Flood, B. E., and Bailey, J. V. (2015). Metatranscriptomic analysis of diminutive Thiomargarita-like bacteria ("Candidatus Thiopilula spp.") from abyssal cold seeps of the Barbados Accretionary Prism. Appl. Environ. Microbiol. 81, 3142-3156. doi: 10.1128/AEM.00039-15

Jones, D. S., Flood, B. E., and Bailey, J. V. (2016). Metatranscriptomic insights into polyphosphate metabolism in marine sediments. ISME J. 10, 1015-1019. doi: 10.1038/ismej.2015.169

Jørgensen, B. B., and Gallardo, V. A. (1999). Thioploca spp.: filamentous sulfur bacteria with nitrate vacuoles. FEMS Microbiol. Ecol. 28, 301-313. doi: 10.1111/j.1574-6941.1999.tb00585.x

Jørgensen, B. B., and Revsbech, N. P. (1983). Colorless sulfur bacteria, Beggiatoa spp. and Thiovulum spp., in $\mathrm{O}_{2}$ and $\mathrm{H}_{2} \mathrm{~S}$ microgradients. Appl. Environ. Microbiol. 45, 1261-1270.

Kalanetra, K. M., Joye, S. B., Sunseri, N. R., and Nelson, D. C. (2005). Novel vacuolate sulfur bacteria from the Gulf of Mexico reproduce by reductive division in three dimensions. Environ. Microbiol. 7, 1451-1460. doi: $10.1111 / j .1462-2920.2005 .00832 . x$

Kanehisa, M., and Goto, S. (2000). KEGG: kyoto encyclopedia of genes and genomes. Nucl. Acids Res. 28, 27-30. doi: 10.1093/nar/28.1.27

Kleiner, M., Petersen, J. M., and Dubilier, N. (2012a). Convergent and divergent evolution of metabolism in sulfur-oxidizing symbionts and the role of horizontal gene transfer. Curr. Opin. Microbiol. 15, 621-631. doi: 10.1016/j.mib.2012.09.003

Kleiner, M., Wentrup, C., Lott, C., Teeling, H., Wetzel, S., Young, J., et al. (2012b). Metaproteomics of a gutless marine worm and its symbiotic microbial community reveal unusual pathways for carbon and energy use. Proc. Natl. Acad. Sci. U.S.A. 109, E1173-E1182. doi: 10.1073/pnas.1121198109

Klotz, M. G., Schmid, M. C., Strous, M., Op Den Camp, H. J. M., Jetten, M. S. M., and Hooper, A. B. (2008). Evolution of an octahaem cytochrome c protein family that is key to aerobic and anaerobic ammonia oxidation by bacteria. Environ. Microbiol. 10, 3150-3163. doi: 10.1111/j.1462-2920.2008. 01733.x

Kojima, H., Ogura, Y., Yamamoto, N., Togashi, T., Mori, H., Watanabe, T., et al. (2015). Ecophysiology of Thioploca ingrica as revealed by the complete genome sequence supplemented with proteomic evidence. ISME J. 9, 1166-1176. doi: 10.1038/ismej.2014.209

Kraft, B., Tegetmeyer, H. E., Meier, D., Geelhoed, J. S., and Strous, M. (2014). Rapid succession of uncultured marine bacterial and archaeal populations in a denitrifying continuous culture. Environ. Microbiol. 16, 3275-3286. doi: $10.1111 / 1462-2920.12552$

Kreutzmann, A.-C. (2013). Electron Donors and Acceptors for Members of the Family Beggiatoaceae. Ph.D. dissertation, Universität Bremen, Bremen.

Kreutzmann, A.-C., and Schulz-Vogt, H. N. (2016). Oxidation of molecular hydrogen by a chemolithoautotrophic Beggiatoa strain. Appl. Environ. Microbiol. 82, 2527-2536. doi: 10.1128/AEM.03818-15

Krogh, A., Larsson, B., von Heijne, G., and Sonnhammer, E. L. (2001). Predicting transmembrane protein topology with a hidden markov model: application to complete genomes. J. Mol. Biol. 305, 567-580. doi: 10.1006/jmbi.2000.4315 
Lagesen, K., Hallin, P., Rødland, E. A., Stærfeldt, H.-H., Rognes, T., and Ussery, D. W. (2007). RNAmmer: consistent and rapid annotation of ribosomal RNA genes. Nucleic Acids Res. 35, 3100-3108. doi: 10.1093/nar/gkm160

Lowe, T. M., and Eddy, S. R. (1997). tRNAscan-SE: a program for improved detection of transfer RNA genes in genomic sequence. Nucleic Acids Res. 25, 0955-0964. doi: 10.1093/nar/25.5.0955

Ludwig, W., Strunk, O., Westram, R., Richter, L., Meier, H., Yadhukumar, et al. (2004). ARB: a software environment for sequence data. Nucleic Acids Res. 32, 1363-1371. doi: 10.1093/nar/gkh293

MacGregor, B. J., Biddle, J. F., Harbort, C., Matthysse, A. G., and Teske, A. (2013a). Sulfide oxidation, nitrate respiration, carbon acquisition, and electron transport pathways suggested by the draft genome of a single orange Guaymas Basin Beggiatoa (Cand. Maribeggiatoa) sp. filamenT. Mar. Genom. 11, 53-65. doi: 10.1016/j.margen.2013.08.001

MacGregor, B. J., Biddle, J. F., Siebert, J. R., Staunton, E., Hegg, E. L., Matthysse, A. G., et al. (2013b). Why orange Guaymas Basin Beggiatoa spp. are orange: single-filament-genome-enabled identification of an abundant octaheme cytochrome with hydroxylamine oxidase, hydrazine oxidase, and nitrite reductase activities. Appl. Environ. Microbiol. 79, 1183-1190. doi: 10.1128/AEM.02538-12

MacGregor, B. J., Biddle, J. F., and Teske, A. (2013c). Mobile elements in a singlefilament orange Guaymas Basin Beggiatoa ("Candidatus Maribeggiatoa") sp. draft genome: evidence for genetic exchange with cyanobacteria. Appl. Environ. Microbiol. 79, 3974-3985. doi: 10.1128/AEM.03821-12

Markert, S., Arndt, C., Felbeck, H., Becher, D., Sievert, S. M., Hügler, M., et al. (2007). Physiological proteomics of the uncultured endosymbiont of Riftia pachyptila. Science 315, 247-250. doi: 10.1126/science.1132913

Markowitz, V. M., Chen, I.-M. A., Palaniappan, K., Chu, K., Szeto, E., Grechkin, Y., et al. (2012). IMG: the integrated microbial genomes database and comparative analysis system. Nucl. Acids Res. 40, D115-D122. doi: 10.1093/nar/gkr1044

McHatton, S. C., Barry, J. P., Jannasch, H. W., and Nelson, D. C. (1996). High nitrate concentrations in vacuolate, autotrophic marine Beggiatoa spp. Appl. Environ. Microbiol. 62, 954-958.

Meyer, F., Goesmann, A., McHardy, A. C., Bartels, D., Bekel, T., Clausen, J., et al. (2003). GenDB - an open source genome annotation system for prokaryote genomes. Nucleic Acids Res. 31, 2187-2195. doi: 10.1093/nar/gkg312

Mezzino, M. J., Strohl, W. R., and Larkin, J. M. (1984). Characterization of Beggiatoa alba. Arch. Microbiol. 137, 139-144. doi: 10.1007/BF00414455

Moreno-Vivián, C., Cabello, P., Martínez-Luque, M., Blasco, R., and Castillo, F. (1999). Prokaryotic nitrate reduction: molecular properties and functional distinction among bacterial nitrate reductases. J. Bacteriol. 181, 6573-6584.

Morozkina, E. V., and Zvyagilskaya, R. A. (2007). Nitrate reductases: structure, functions, and effect of stress factors. Biochemistry (Mosc.) 72, 1151-1160. doi: $10.1134 / \mathrm{S} 0006297907100124$

Muntyan, M. S., Grabovich, M. Y., Patritskaya, V. Y., and Dubinina, G. A. (2005). Regulation of metabolic and electron transport pathways in the freshwater bacterium Beggiatoa leptomitiformis D-402. Microbiology 74, 388-394. doi: 10.1007/s11021-005-0078-8

Mußmann, M., Hu, F. Z., Richter, M., de Beer, D., Preisler, A., Jørgensen, B. B., et al. (2007). Insights into the genome of large sulfur bacteria revealed by analysis of single filaments. PLoS Biol. 5:e230. doi: 10.1371/journal.pbio.0050230

Nelson, D. C., and Castenholz, R. W. (1981). Organic nutrition of Beggiatoa sp. J. Bacteriol. 147, 236-247.

Nelson, D. C., and Jannasch, H. W. (1983). Chemoautotrophic growth of a marine Beggiatoa in sulfide-gradient cultures. Arch. Microbiol. 136, 262-269. doi: $10.1007 / \mathrm{BF} 00425214$

Noguchi, H., Park, J., and Takagi, T. (2006). MetaGene: prokaryotic gene finding from environmental genome shotgun sequences. Nucleic Acids Res. 34, 5623 5630. doi: 10.1093/nar/gkl723

Otte, S., Kuenen, J. G., Nielsen, L. P., Paerl, H. W., Zopfi, J., Schulz, H. N., et al. (1999). Nitrogen, carbon, and sulfur metabolism in natural Thioploca samples. Appl. Environ. Microbiol. 65, 3148-3157.

Petersen, J. M., Zielinski, F. U., Pape, T., Seifert, R., Moraru, C., Amann, R., et al. (2011). Hydrogen is an energy source for hydrothermal vent symbioses. Nature 476, 176-180. doi: 10.1038/nature10325

Prince, R. C., Stokley, K. E., Haith, C. E., and Jannasch, H. W. (1988). The cytochromes of a marine Beggiatoa. Arch. Microbiol. 150, 193-196. doi: 10.1007/BF00425161
Prokopenko, M. G., Hirst, M. B., De Brabandere, L., Lawrence, D. J. P., Berelson, W. M., Granger, J., et al. (2013). Nitrogen losses in anoxic marine sediments driven by Thioploca-anammox bacterial consortia. Nature 500, 194-198. doi: $10.1038 /$ nature 12365

Pruesse, E., Peplies, J., and Glöckner, F. O. (2012). SINA: accurate high-throughput multiple sequence alignment of ribosomal RNA genes. Bioinformatics 28, 18231829. doi: 10.1093/bioinformatics/bts252

Quast, C. (2006). MicHanThi - Design and Implementation of a System for the Prediction of Gene Functions in Genome Annotation Projects. diploma thesis, Universität Bremen, Bremen.

Quast, C., Pruesse, E., Yilmaz, P., Gerken, J., Schweer, T., Yarza, P., et al. (2012). The SILVA ribosomal RNA gene database project: improved data processing and web-based tools. Nucleic Acids Res. 41, D590-D596. doi: 10.1093/nar/gks 1219

Ramaswamy, K. S., Carrasco, C. D., Fatma, T., and Golden, J. W. (1997). Celltype specificity of the Anabaena $f d x N$-element rearrangement requires $x i s H$ and xisl. Mol. Microbiol. 23, 1241-1249. doi: 10.1046/j.1365-2958.1997.30 81671.x

Reshetnikov, A. S., Rozova, O. N., Khmelenina, V. N., Mustakhimov, I. I., Beschastny, A. P., Murrell, J. C., et al. (2008). Characterization of the pyrophosphate-dependent 6-phosphofructokinase from Methylococcus capsulatus Bath. FEMS Microbiol. Lett. 288, 202-210. doi: 10.1111/j.15746968.2008.01366.x

Richter, M., Lombardot, T., Kostadinov, I., Kottmann, R., Duhaime, M. B., Peplies, J., et al. (2008). JCoast - A biologist-centric software tool for data mining and comparison of prokaryotic (meta)genomes. BMC Bioinformatics 9:177. doi: 10.1186/1471-2105-9-177

Salman, V., Amann, R., Girnth, A.-C., Polerecky, L., Bailey, J. V., Høgslund, S., et al. (2011). A single-cell sequencing approach to the classification of large, vacuolated sulfur bacteria. Syst. Appl. Microbiol. 34, 243-259. doi: 10.1016/j.syapm.2011.02.001

Salman, V., Amann, R., Shub, D. A., and Schulz-Vogt, H. N. (2012). Multiple selfsplicing introns in the $16 \mathrm{~S}$ rRNA genes of giant sulfur bacteria. Proc. Natl. Acad. Sci. U.S.A. 109, 4203-4208. doi: 10.1073/pnas.1120192109

Salman, V., Bailey, J. V., and Teske, A. (2013). Phylogenetic and morphologic complexity of giant sulphur bacteria. Antonie Van Leeuwenhoek 104, 169-186. doi: $10.1007 /$ s10482-013-9952-y

Schulz, H. N. (2006). "The genus Thiomargarita", in The Prokaryotes, eds M. D. S. Falkow, E. Rosenberg, K.-H. Schleifer, and E. Stackebrandt (New York, NY: Springer), 1156-1163.

Schulz, H. N., Brinkhoff, T., Ferdelman, T. G., Mariné, M. H., Teske, A., and Jørgensen, B. B. (1999). Dense populations of a giant sulfur bacterium in Namibian shelf sediments. Science 284, 493-495. doi: $10.1126 /$ science. 284.5413 .493

Schulz, H. N., and de Beer, D. (2002). Uptake rates of oxygen and sulfide measured with individual Thiomargarita namibiensis cells by using microelectrodes. Appl. Environ. Microbiol. 68, 5746-5749. doi: 10.1128/AEM.68.11.5746-5749. 2002

Schulz, H. N., and Schulz, H. D. (2005). Large sulfur bacteria and the formation of phosphorite. Science 307, 416-418. doi: 10.1126/science.1103096

Schwedt, A., Kreutzmann, A.-C., Polerecky, L., and Schulz-Vogt, H. N. (2012). Sulfur respiration in a marine chemolithoautotrophic Beggiatoa strain. Front. Microbiol. 2:276. doi: 10.3389/fmicb.2011.00276

Stepanova, I. Y., Eprintsev, A. T., Falaleeva, M. I., Parfenova, N. V., Grabovich, M. Y., Patritskaya, V. Y., et al. (2002). Dependence of malate dehydrogenase structure on the type of metabolism in freshwater filamentous colorless sulfur bacteria of the genus Beggiatoa. Microbiology 71, 377-382. doi: 10.1023/A:1019825006330

Strittmatter, A. W., Liesegang, H., Rabus, R., Decker, I., Amann, J., Andres, S., et al. (2009). Genome sequence of Desulfobacterium autotrophicum HRM2, a marine sulfate reducer oxidizing organic carbon completely to carbon dioxide. Environ. Microbiol. 11, 1038-1055. doi: 10.1111/j.1462-2920.2008.01825.x

Strohl, W. R., Schmidt, T. M., Vinci, V. A., and Larkin, J. M. (1986). Electron transport and respiration in Beggiatoa and Vitreoscilla. Arch. Microbiol. 145, 71-75. doi: 10.1007/BF00413029

Sweerts, J.-P. R. A., Beer, D. D., Nielsen, L. P., Verdouw, H., den Heuvel, J. C. V., Cohen, Y., et al. (1990). Denitrification by sulphur oxidizing Beggiatoa spp. mats on freshwater sediments. Nature 344, 762-763. doi: 10.1038/344762a0 
Tanaka, S., Lee, S.-O., Hamaoka, K., Kato, J., Takiguchi, N., Nakamura, K., et al. (2003). Strictly polyphosphate-dependent glucokinase in a polyphosphateaccumulating bacterium, Microlunatus phosphovorus. J. Bacteriol. 185, $5654-$ 5656. doi: 10.1128/JB.185.18.5654-5656.2003

Taylor, S. C., Dalton, H., and Dow, C. S. (1981). Ribulose-1,5-bisphosphate carboxylase/oxygenase and carbon assimilation in Methylococcus capsulatus (Bath). J. Gen. Microbiol. 122, 89-94. doi: 10.1099/00221287-12 2-1-89

Teske, A., and Salman, V. (2014). "The family beggiatoaceae," in The Prokaryotes, eds E. Rosenberg, E. F. DeLong, S. Lory, E. Stackebrandt, and F. Thompson (Berlin: Springer), 93-134.

Thauer, R. K., Kaster, A.-K., Seedorf, H., Buckel, W., and Hedderich, R. (2008). Methanogenic archaea: ecologically relevant differences in energy conservation. Nat. Rev. Micro. 6, 579-591. doi: 10.1038/nrmicro1931

Treude, T., Boetius, A., Knittel, K., Wallmann, K., and Jørgensen, B. B. (2003). Anaerobic oxidation of methane above gas hydrates at Hydrate Ridge, NE Pacific Ocean. Mar. Ecol. Prog. Ser. 264, 1-14. doi: 10.3354/meps 264001

Vargas, A., and Strohl, W. R. (1985). Utilization of nitrate by Beggiatoa alba. Arch. Microbiol. 142, 279-284. doi: 10.1007/BF00693404

Walsh, K., and Koshland, D. E. (1984). Determination of flux through the branch point of two metabolic cycles. The tricarboxylic acid cycle and the glyoxylate shunt. J. Biol. Chem. 259, 9646-9654.

Ward, N., Larsen, Ø, Sakwa, J., Bruseth, L., Khouri, H., Durkin, A. S., et al. (2004). Genomic insights into methanotrophy: the complete genome sequence of Methylococcus capsulatus (Bath). PLoS Biol. 2:e303. doi: 10.1371/journal.pbio.0020303

Winkel, M., de Beer, D., Lavik, G., Peplies, J., and Mußmann, M. (2014). Close association of active nitrifiers with Beggiatoa mats covering deep-sea hydrothermal sediments. Environ. Microbiol. 16, 1612-1626. doi: 10.1111/14622920.12316

Wood, A. P., Aurikko, J. P., and Kelly, D. P. (2004). A challenge for 21st century molecular biology and biochemistry: what are the causes of obligate autotrophy and methanotrophy? FEMS Microbiol. Rev. 28, 335-352. doi: 10.1016/j.femsre.2003.12.001

Zerbino, D. R., and Birney, E. (2008). Velvet: algorithms for de novo short read assembly using de Bruijn graphs. Genome Res. 18, 821-829. doi: $10.1101 /$ gr.074492.107

Conflict of Interest Statement: The authors declare that the research was conducted in the absence of any commercial or financial relationships that could be construed as a potential conflict of interest.

Copyright (c) 2016 Winkel, Salman-Carvalho, Woyke, Richter, Schulz-Vogt, Flood, Bailey and Mußmann. This is an open-access article distributed under the terms of the Creative Commons Attribution License (CC BY). The use, distribution or reproduction in other forums is permitted, provided the original author(s) or licensor are credited and that the original publication in this journal is cited, in accordance with accepted academic practice. No use, distribution or reproduction is permitted which does not comply with these terms. 